Please do not destroy or throw away this publication. If you have no further use for it, write to the Geological Survey at Washington and ask for a frank to return it

UNITED STATES DEPARTMENT OF THE INTERIOR

Harold L. Ickes, Secretary

GEOLOGICAL SURVEY

w. C. Mendenhall, Director

Professional Paper 175-D

\title{
ORIGIN OF THE ANHYDRITE CAP ROCK OF AMERICAN SALT DOMES
}

BY

\author{
MARCUS I. GOLDMAN
}

Shorter contributions to general geology, 1932-33

(Pages 83-114)

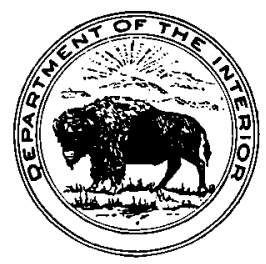

UNITED STATES

GOVERNMENT PRINTING OFFICE

WASHINGTON : 1933

For sale by the Superintendent of Documents, Washington, D. C. - . - Price 15 cents 


\section{CONTENTS}

Abstract...................

Introduction $\ldots$

Terminology . . . . . . . . . . . . . . . . . . . .

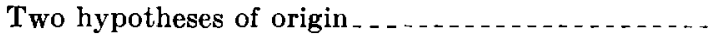

The process of origin of cap rock by residual accumula-

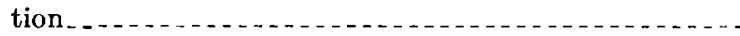

Considerations and evidence in support of the hypothesis of origin by residual accumulation. . . . . . . . . .

Evidence from the breccia fragments . ........... Sedimentary origin of the breccia fragments... Primary katatectic cap rock............. Three hypotheses of brecciation........... An intraformational sedimentary breccia. .

A brecciated overlying bed or a residual breccia

The parallel bands (katatectic bands) . . . . . . . . Examples of katatectic banding .......... Hypotheses of origin of katatectic banding. ...

\begin{tabular}{|c|c|c|}
\hline $\begin{array}{r}-12 \\
83\end{array}$ & $\begin{array}{l}\text { Considerations and evidence in support of the hypothesis } \\
\text { of origin by residual accumulation-Continued. }\end{array}$ & \\
\hline 83 & The parallel bands (katatectic bands)-Con. & Page \\
\hline 83 & $\begin{array}{l}\text { Considerations and evidence in support of the } \\
\text { origin of katatectic banding and of the }\end{array}$ & \\
\hline 86 & $\begin{array}{l}\text { hydrite cap rock in general by residual ac- } \\
\text { cumulation }\end{array}$ & 90 \\
\hline $\begin{array}{l}88 \\
88\end{array}$ & $\begin{array}{l}\text { Probability of periodicity in residual ac- } \\
\text { cumulation }\end{array}$ & \\
\hline 8 & Differences from shear surfaces. . . . . . . . & 91 \\
\hline 8 & The salt table. & 92 \\
\hline 88 & The contact of salt and anhydrite & 92 \\
\hline $\begin{array}{l}88 \\
89\end{array}$ & Probable relation of an overlying bed of & \\
\hline & Variations in thickness of cap rock..... & \\
\hline & or absence of cap rock & 93 \\
\hline & Acknowledgments $\ldots$ & \\
\hline & & \\
\hline
\end{tabular}

\section{ILLUSTRATIONS}

Plate 24. Figure 1. General view of a band of impure salt, carrying disseminated anhydrite crystals, from one of the Five Islands salt domes, Louisiana. Figure 2. Polished face of same specimen enlarged.

25. Figure 3. Anhydrite crystals residual from the solution of salt from shaft on Hockley salt dome, Texas. Figure 4. Anhydrite crystals residual from the solution of the band of impure salt illustrated in figures 1 and 2

26. Figures 5 and 6 . General views of a specimen of salt with lenses of disseminated anhydrite from Brenham salt dome, Texas. Figure 7. Detail of polished face of same specimen.

27. Figure 8. Contact of banded anhydrite cap rock and salt from Hockley salt dome, Harris County, Tex

28. Figure 9. General view of thin section 5 from preceding specimen, showing the contact of the lowest anhydrite band with the one above it. Figure 10. General view of thin section 2 of same specimen, showing the contact of two higher bands

29. Figure 11. Detail of preceding thin section 2 showing the irregular distribution of impurities along the contact of two bands

30. Figures 12 and 13. Detail of thin section 5 showing slight strain and crushing along contact of bands.....................

31. Figures 14 and 15. Detail of figure 10, showing straining, but without appreciable crushing, within a katatectic band.
Page

Plate 32. Figures 16 and 17. Detail of thin section 2 showing a crushed patch not along the contact of two bands. . . . . . . . . . . . . .

33. Figures 18 and 19. Detail of figure 11 showing carbonate and crushing along the contact of two bands. . . . . . . . . . . . .

34. Figure 20. Solid primary sedimentary anhydrite rock with no recognizable stratification seams. Figure 21. A large fragment of primary sedimentary ar'ydrite with unusually clear and pronounced but widely spaced stratification seams showing distortion. Figure 22. A core consisting apparently almost entirely of primary sedimentary anhydrite rock but very much brecciated. Figure 23. Largest single piece of well-stratified primary sedimentary anhydrite rock encountered in diamonddrill core . . . . . . . . . . . . . . . . . . . .

35. Figure 24. An unusually long core showing primary katatectic anhydrite cap rock with unusually long intervals showing little or no katatectic banding adjacent to well-defined katatectic bands. Figure 25. Specimen showing considerable thicknesses of primary katatectic anhydrite cap rock, with little or no recognizable banding, in association with pronounced katatectic banding

36. Figures 26 and 27. Specimen from contact of salt and anhydrite cap rock on Bay St. Elaine salt dome, Terrebonne Parish, La_-
Page 
37. Figure 28. Specimen, from diamond-drill core, that shows the best example of a breccia fragment of stratified sedimentary anhydrite cap rock. Figure 29. Another example of a breccia fragment showing distinct stratification but with the stratification surfaces more widely spaced than in figure 28. Figure 30. Photomicrograph of a thin section of specimen illustrated in figure 28, showing the appearance of the impurities along the stratification surfaces and something of the relation of the breccia fragment to its matrix.

38. Figure 31. Detail of figure 32 , at contact of matrix and clast. Figure 32. Photomicrograph of thin section 4, figure 29, illustrating the relation of breccia fragment and matrix

39. Figure 33. Photomicrograph of thin section 1 , Figure 27, showing a particularly clearly stratified breccia fragment of primary sedimentary anhydrite cap rock and its matrix. Figure 34. Detail of preceding at contact of clast and matrix

40. Figures 35 and 36 . Examples of ordinary katatectic anhydrite cap rock showing less sharply defined breccia fragments. Figure 37. Specimen from diamond-drill core most typically illustrating katatectic banding, the banding close and sharp and without recognizable breccia fragments in the bands. Figures 38 and 39. Two specimens from diamond-drill core showing pronounced katatectic banding but the banding unusually converging and irregular

41. Figure 40. A rather unusual example of schistosity in the cap rock of the Sulphur salt dome. Figure 41. An example of curving schistosity parallel to a curving surface of parting unusual in the Sulphur cap rock. Figure 42. Diagram showing gypsum-anhydrite cap rock overlying complex folds, including an anhydrite bed, in a German salt stock. Figure 43. Diagram showing a more complex relation between gypsumanhydrite cap rock and the anhydrite of the salt stock in a German salt dome. Figure 44. Diagram showing a bed of anhydrite projecting above the salt table into the overlying gypsum-anhydrite cap rock on a German salt dome...........

42. Figures 45 and 46 . Core from depth of about 950 feet on Hockley salt dome, Harris County, Tex., showing a breccia of calcareous rock fragments in sandy clay .......
Page 



\title{
ORIGIN OF THE ANHYDRITE CAP ROCK OF AMERICAN SALT DOMES
}

\author{
By Marcus I. Goldman
}

\begin{abstract}
The thesis of this paper is that the anhydrite cap rock of salt domes originated by the residual accumulation and consolidation, on top of a salt stock, of sedimentary anhydrite freed from the salt by solution of the top of the stock. This hypothesis is compared with that of origin from a bed of sedimentary anhydrite supposed to have overlain the salt of the salt stock in depth and to have been forced up on top of the stock as it rose. The strongest basis for the hypothesis of residual accumulation is the presence, between the anhydrite cap rock and the top of the salt stock on many salt domes, of a flat solution surface, the "salt table," decapitating anhydrite-bearing folds in the salt. The paper considers other general geologic evidence and internal petrographic evidence with a view to ascertaining to what extent they confirm or at least fit this interpretation. The cap rock contains breccia fragments of bedded sedimentary anhydrite. These cannot be of intraformational sedimentary origin, because similar bedded anhydrite is nowhere found in normal interbedded relations in the cap rock. Therefore, if the anhydrite cap rock is derived from a sedimentary bed which overlay the salt, that bed has been brecciated and recemented since the intrusion of the salt stock. Anhydrite cap rock is also characterized by roughly flat and parallel bands lying horizontal or at low dips, here named katatectic bands. If the breccia fragments, which lie within these bands, were produced by brecciation after sedimentation, the bands themselves can not be of primary sedimentary origin. The hypotheses of their origin by shearing or by periodicity in the process of residual accumulation are compared.

Considerations favoring the origin of the katatectic banding by residual accumalation are (a) the probability of periodicity in residual accumulation; (b) the difference of the katatectic surfaces from shear surfaces in their lack of convergence, their wide spacing, and their occurrence directly above the flat salt table; and (c) the absence of appreciable crushing along them in this and most other positions.

General considerations favoring the residual origin of the anhydrite cap rock are the presence of a layer of brine and anhydrite sand at the contact of salt and anhydrite on several salt stocks; the common occurrence of the relatively flat salt table on top of salt stocks; the consideration that if during the formation of a stock the pressure of a bed of salt shattered an overlying bed of anhydrite, it would probably engulf the fragments of that bed, and so a cap rock derived from such an overlying bed of anhydrite would, in the end, also be formed by residual accumulation; and the variations in the thickness of the cap rock, which are more readily accounted for by residual accumulation of anhydrite interbedded in the salt stock than by derivation from an overlying sedimentary bed. The absence of cap rock on certain salt stocks is not accounted for, but the suggestion is made that it may be due to gypsification at lesser depths, accompanied by too active circulation of water, with consequent solution of calcium sulphate as well as of salt, favored, on some stocks, by the absence of beds of sedimentary anhydrite rock in the salt stock; or that a cap rock may not yet have had time to form.

\section{INTRODUCTION \\ TERMIN OLOGY}

To avoid confusion in the nomenclature of salt domes it is suggested that the word "dome" be restricted to the surface uplift marking the presence of a salt intrusion, and that "stock" be used for the intruded body of salt, which may not have affected the surface at all. The word "core" has been used for this intruded body, but as the salt is often cored in drilling on salt domes the use of that word opens the way for confusion. This use of the word "stock" conforms to its general use in geology.

As gypsification of the anhydrite cap is common it will be necessary, where its existence as anhydrite is not specifically in question, to refer to it as the gypsumanhydrite cap.

\section{TWO HYPOTHESES OF ORIGIN}

The two hypotheses of the origin of anhydrite cap rock to be considered in this paper are (1) that the cap rock is derived from an original bed of sedimentary anhydrite which overlay the salt of the salt stock in depth and was pushed up on top of the stock during its intrusion into the overlying beds, and that during its upward progress the bed of anhydrite was brecciated, and the breccia, recemented, makes up the cap rock; ${ }^{1}$ (2) that it is formed by the cementation and consolidation, on top of the salt stock, of grains of anhydrite and fragments of anhydrite rock freed from the salt stock by solution of its upper end. ${ }^{2}$

Hereinafter the terms "sedimentary hypothesis," "sedimentary origin," etc., will be used in reference to a cap rock formed according to the first of these hypotheses; "residual hypothesis," "residual origin," etc., in reference to one formed according to the second hypothesis. The residual hypothesis is the one advocated in this paper.

The mere presence of breccia fragments of beds of sedimentary anhydrite, which led to the acceptance of the sedimentary hypothesis in my earlier paper (1925), seems, in the absence of more detailed analysis of the

1 Cf. Goldman, M. I., Petrography of salt-dome cap rock: Am. Assoc. Petroleum Geologists Bull., vol. 9, No. 1, pp. 42-79, 1925; also in DeGolyer, E. L., and others, Geology of salt-dome oil fields, pp. 50-86, 1926. Brown, L. S., Cap-rock petrography: Am. Assoc. Petroleum Geologists Buil., vol, 15, No. 5, pp. 509-529, 1931.

2 Goldman, M. I., Features of gypsum-anhydrite salt-dome cap rock [abstract]: Geol. Soc. America Bull., vol. 40, No. 1, pp. 99-100, 1929; discussion of Brown, L. S., Cap-rock petrography: Am. Assoc. Petroleum Geologists Bull., vol. 15, No. 5, pp. 525-527, 1931; Bearing of cap rock on subsidence on Clay Creek salt dome: Idem, vol. 15, No. 9, pp. 1105-1113, 1931.
\end{abstract}


problem, as favorable to one as to the other of these hypotheses. The strongest petrographic evidence in favor of the residual hypothesis is supplied by the roughly parallel bands, generally horizontal or dipping at low angles, which occur throughout the cap rock and which were discussed but not explained in the paper of 1925 .

As a substitute for the long phrase, "roughly parallel bands, generally horizontal or dipping at low angles"

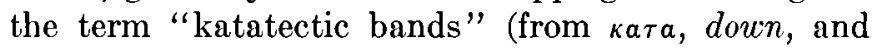
$\tau \epsilon \kappa \tau \epsilon(\nu$, to build) is used in this paper. The surfaces bounding these bands are called "katatectic surfaces."

It will not do to call the structure merely "banding" because the important consideration is to differentiate it from the banding of the included breccia fragments and to a certain extent from flow or schistosity banding. It is, to be sure, a type of stratification, but as such it must be differentiated from two other types of stratification that come into question in the interpretations of the origin of cap rock. One of these is the banding, which I regard as stratification, in the breccia fragments. The other is normal sedimentary stratification of the cap rock as a whole, which these katatectic bands are by some supposed to represent.

The outstanding and most weighty general geologic fact pointing to the residual interpretation is the presence, on top of the salt stock and under the gypsum-anhydrite cap rock of many or most American salt domes, of a flat solution surface or salt table such as is found also on most German domes. Much evidence for this is contained in the volume on salt-dome oil fields. ${ }^{3}$

It is obvious in cross sections of German salt domes, such as those reproduced in figures 42 and 43 (pl. 41), that the salt table decapitates folded salt including beds of anhydrite. No plausible process other than solution of the salt suggests itself, and, as far as I know, no other has been suggested for this decapitation. The fact that the salt stocks of American salt domes have been extruded from depth makes it highly probable that they also have been complexly folded. Where penetrated by mine workings, as in the Five Islands, ${ }^{4}$ such folding is found. Beds of salt dipping $70^{\circ}$ were also encountered in the salt stock of the Grand Saline salt dome, Van Zandt County, Tex. ${ }^{5}$

Theoretical considerations and observation therefore indicate that on American salt stocks, as on the German, complexly folded beds are decapitated by the salt table.

In all the mine workings just mentioned and in those on the Hockley salt stock, Harris County, Tex., ${ }^{5}$ the bedding, represented by the so-called "annual layers" in the salt, is defined by dark layers carrying dissem-

\footnotetext{
${ }^{3}$ DeGolyer, E. L., and others, op. cit.

1 Vaughan, F. E., The Five Islands, in DeGolyer, E. L., and others, op. cit., pp. 356-397, especially fig. 5 , p. 369,1926 .

5 Letter to the writer from L. P. Teas, of the Humble Oil \& Refining Co., May 16. 1931.
}

inated anhydrite crystals. (See figs. 1 to 4 , pls. 24,25 .)

From what follows it will appear that, if the residual theory is accepted, the occurrence of breccia fragments of solid beds of sedimentary anhydrite rock in the cap rock proves that anhydrite in this form also is present in the salt stocks of American salt domes. But adequately verified records of the finding of such beds in these salt stocks seem to be lacking. Howe and Moresi ${ }^{6}$ have gathered records of supposed occurrences of anhydrite rock in Texas and Louisiana salt stocks, but none of these can be regarded as well authenticated or conclusive.

With the help of Dr. Donald C. Barton, of Houston, and through the generosity of Mr. Fitzsimmons I obtained the specimen of interbanded salt and anhydrite-bearing salt from a depth of 2,172 feet in the Fitzsimmons No. 1 well, on the Brenham dome, Washington and Austin Counties, Tex., to which Howe and Moresi refer. It is illustrated in figures 5, 6 , and 7 (pl. 26). This specimen, as sketched from memory, was illustrated by Doctor Barton. ${ }^{7}$ Although he recognized in his description the gradation between the bands, his sketch makes them appear straighter and more regular and, therefore, more like true beds than they are. The purer salt was evidently more extensively dissolved in coring than the more anhydritic salt, and the lenticular relations of the two types of material are thereby brought out, as shown in figures 5 and 6 . Figure 7 shows the termination, in the anhydritic salt of the polished face, of a lens of pure salt. This figure also shows that none of the anhydrite is aggregated into solid rock but that all of it is disseminated through the salt and that it is of the type of that which occurs in the annual layers and which forms the matrix of the anhydrite cap rock (cf. figs. 2 to 4 , pls. 24 and 25 , and figs. 9 to 19 , pls. 28 to 33 ), not the fine-grained, equant type of that which makes up the clasts (ef. figs. 30 to 34 , pls. 37 to $39)$.

It seems probable that the lenticular relations of the two types of material are due to flowage in the salt stock, involving bands of disseminated anhydrite in the salt.

As the specimen in question occurs in an interval, extending from 2,100 to 2,200 feet, reported as "interbedded salt and anhydrite", 8 it may be assumed that the entire interval contained the same sort of material, not true anhydrite rock.

The accumulation of such a thickness of this material may be due to original deposition of an unusually large proportion of layers of disseminated anhydrite; or it may be that the anhydritic salt reacted as a less plastic rock and accumulated, by squeezing out of the inter-

' Howe, H. V., and Moresi, C. K., Geology of Iberia Parish: Louisiana Dept. Conservation Geol. Bull. 1, p. 118, 1931.

${ }^{7}$ Barton, D. C., Salt domes of south Texas, in DeGolyer, E. L., and others, op. cit.. fig. 8, p. 755, 1926; Am. Assoc. Petroleum Geologists Bull., vol. 9, No. 3, p. 573, 1925. 8 Barton, D. C., op. cit., 1926, p. 754; 1925, p. 572. 
vening more plastic salt ${ }^{9}$; or it may have accumulated within the stock by solution of the salt.

Howe and Moresi base their record of the occurrence of anhydrite rock in the salt of the Hockley salt stock on the statement by Chapman ${ }^{10}$ that "specimens of the rock salt encountered show some anhydrite in the upper part of the deposit." This is, I believe, more properly interpreted as indicating anhydrite grains rather densely disseminated in salt than solid beds of anhydrite. The shaft recently sunk into the Hockley salt stock has encountered salt with unusually large amounts of disseminated anhydrite crystals.

It is from a specimen of such impure salt kindly supplied by Dr. Marcus A. Hanna, of Houston, Tex., that the crystals illustrated in figure 3 were obtained. As I have seen it, this material has even less the character of anhydrite rock than the specimen of figures 5, 6, and 7 from the Fitzsimmons well. In reply to a specific inquiry regarding the occurrence of anhydrite rock in the Hockley salt, Dr. Hanna writes on April 16, 1932:

I went to Hockley day before yesterday in order to learn as much as possible about the recent development in the shaft. The shaft is now at a depth of slightly below 1,450 feet, or approximately 450 feet below the base of the massive anhydrite [cap]. Within this 450 feet of salt nothing in the way of anhydrite other than more or less homogeneously distributed anhydrite erystals has been found. In other words, to the present depth of the shaft no bedded anhydrite is present. Further than that, some core drilling has been done from the bottom of the shaft, and in this core drilling no solid anhydrite has been found. One core drill hole was drilled vertically from the bottom of the shaft to somewhat below 2,000 feet. This gives a known section of salt from the base of the anhydrite [cap] at 1,010 feet of slightly over 1,000 feet. This material has been very carefully examined, and in none of it has any solid anhydrite apyeared. From this and the other core holes we may conclude that with the rather extensive exploration so far carried out at the Hockley dome, nothing but disseminated anhydrite is present.

In the $\log$ of the Knapp No. 1 well on the Belle Isle salt dome, ${ }^{11}$ to which Howe and Moresi refer, anhydrite is reported at several levels. No samples of this material appear any longer to be available, so that the determination cannot be verified. Certain inconsistencies between the verbal $\log$ as given by Lucas on page 1037 and a graphic $\log$ as given in his figure 2 on page 1045 might raise doubts as to the accuracy of the record. The association of anhydrite and sulphur at a depth of 2,606 to 2,628 feet also raises doubts, in case a considerable proportion of sulphur is implied. So far as I have observed, abundant sulphur in cap rock is invariably associated with calcium carbonate. $\Lambda$ side from possible uncertainties in the record, also, both the paper by Lucas and the discussion of Belle

${ }^{9}$ Cf. Seidl, Erich, Die permische Salzlagerstätte im Graf Moltke schacht: Archiv für Lagerstăttenforschung, Heft 10, Berlin, K. preuss. geol. Landesanstalt, 1914.

1) Chapman, L. C., The Hockley salt dome: Am. Assoc. Petroleum Geologists Pull., vol. 7, No. 3, p. 298, 1923.

$"$ See Lucas, A. F., A review of explorations at Belle Isle, I.a.: Am. Inst. Min. Eng. Trans., vol. 17, pp. 1034-1049, 1917.
Isle by Vaughan ${ }^{12}$ indicate complex conditions which suggest engulfing of surrounding sediments by the salt, so that evidence as to the original condition of the salt is by that much more uncertain. However, it may be concluded that, although the observations cannot be checked, there is considerable evidence for the occurrence of anhydrite rock in the salt of Belle Isle.

I have been unable to check the reported occurrence of gypsum at a depth of 2,260 feet- $-1,360$ feet below the top of the salt-in Drake's salt dome. ${ }^{13}$ It is improbable, however, that gypsum was encountered 2,260 feet below the surface, as the prevailing evidence indicates that anhydrite is the stable form of calcium sulphate at such depths.

There is much confusion in the differentiation of calcite rock, anhydrite, and gypsum by drillers on the salt domes of Texas and Louisiana. The records of the presence of beds of anhydrite rock in American salt stocks must, therefore, be regarded as inconclusive. That such beds have not been encountered or more frequently encountered there may be due to the fact that the beds, though present, are thinner than those in the salt of German salt stocks (cf. fig. 44, pl. 41) and so have been more fractured and dispersed by flowage of the salt; or that the salt has flowed more intensely than in the German stocks, with the same result. The resulting fragments should be encountered in the salt but might be overlooked more readily than a con tinuous bed of anhydrite rock.

As pointed out above, however, the presence of beds or fragments of beds of anhydrite rock in American salt stocks is established by the indirect evidence of the cap rock itself, if the theory of the residual origin of the cap is accepted.

According to that theory the solution which produces the salt table would be likely to leave any anhydrite contained in the salt as a residue. The gypsum-anhydrite cap rock lying on the salt table unconformably across the beds of the underlying stock, and containing fragments of what I interpret as primary sedimentary anhydrite rock, is taken to be this residually accumulated anhydrite. In fact, it is highly improbable that a gypsum-anhydrite cap would be present in this position and not be derived, at least in part, from anhydrite freed by solution of the top of the salt stock. Figures 42,43 , and 44 (pl. 41) furnish examples of the relation of the gypsum-anhydrite cap rock to the salt stock and its contained anhydrite beds on German domes.

Figure 42 is significant as showing the close and complex folding and the large amount of decapitation. The gypsum-anhydrite cap rock must, however, have been derived from beds higher in the series than the anhydrite bed shown in the cross section, as very little of that has been decapitated. But in the sec-

12 Vaughan, F. E., The Five Islands, La., in De Golyer, E. L., and others, op. cit., pp. 383-392; Am. Assoc. Petroleum Geologists Bull., vol. 9, No. 4, pp. 783-792, 1925

13 Spooner, W. C., Interior salt domes of Louisiana, in De Golyer, E. L., and others, op. cit., p. 327; Am. Assoc. Petroleum Geologists Bull., vol. 10, No. 3, p. 275, 1926. 
tion shown in figure 43 the distribution of the gypsumanhydrite cap can, as pointed out in the description of that figure, to a certain extent be directly correlated with its distribution in the underlying stock. In figure 44 the intimate association of gypsumanhydrite cap rock and an anhydrite bed contained in the salt is strikingly brought out, apparently on the basis of the concrete evidence afforded by a shaft, by the bed of sedimentary anhydrite projecting from the salt into the cap rock. This relationship seems to prove pretty definitely that the gypsumanhydrite cap rock is not an unfragmented bed of sedimentary anhydrite which overlies the salt in depth. It also seems to make almost inescapable, when considered in connection with figures 42 and 43, the conclusion that it consists largely, if not entirely, of anhydrite residual from the solution of the salt stock. For if gypsum or anhydrite has survived or accumulated here to form a cap, that residual from solution of the salt stock must be a large part of such a cap and may well be all of it.

Specimens from the contact of salt and cap rock received since the earlier paper was written have also clarified and tended to confirm the interpretation, arrived at from these general geologic relations and from the katatectic bands in the cap rock, of origin by residual accumulation. According to that interpretation this cap rock at the contact with the salt would be the most recently formed and would therefore be more likely than higher parts to give clear and trustworthy evidence about its origin. The following pages are given to the consideration of the extent to which other general geologic facts and internal petrographic evidence confirm or fit the residual theory of the origin of the cap rock. Before the evidence is discussed a fuller presentation of my conception of the process of residual accumulation is desirable.

\section{THE PROCESS OF ORIGIN OF CAP ROCK BY RESIDUAL ACCUMULATION}

The formation of the cap rock begins with the solution of the unprotected top of the salt core by water from some bed that it penetrated or at the surface of the earth. Once a protective cap has been formed by such a process, it is assumed that in some way ${ }^{14}$ water from the same or a different source finds its way along the contact between salt and anhydrite cap and that the salt continues to be dissolved and removed in solution. In the process that forms the katatectic bands and surfaces, various factors tend to preserve for a time an open space between the cap rock and the top of the salt stock as this solution goes on. The closing of the space may be due to descent of the cap rock, to rise of the salt

\footnotetext{
"1 See Goldman, M. I., Bearing of cap rock on subsidence on Clay Creek salt
} dome: Am. Assoc. Petroleum Geologists Bull., vol. 15, No. 9, pp. 1105-1113, 1931. stock, or to both. If it is due to descent of the cap rock, friction and cohesion might delay this descent. It is believed, for instance, that most anhydrite caps extend not only across the top of the salt stock but also a certain distance down its flanks, though it is surprising to discover how few definite examples of this relationship have been recorded. In seeking evidence on this, as on many other features of salt domes, it is necessary to distinguish carefully between facts founded on definite observations on the particular salt dome in question, and extrapolations on the basis of assumptions acquired from other occurrences.

Thus, while the Geology of Salt-Dome Oil Fields contains several illustrations of cap rock extending down the flanks of the salt stock, only three were noted that showed definite evidence of such a relationship. These were figure 4 of Barton's paper on Pine Prairie (p. 428); figure 3 of Aplin's paper on Stratton Ridge (p. 654); and figure 4 of Barton's paper on salt domes of south Texas (p. 726). However, where flank cap rock is present there would be a certain amount of frictional resistance along its outside surface-that is to say, between flank cap rock and surrounding sediments-tending to hold up the cap. On the inside of the flanking cap rock, on the other hand, the space separating it from the salt stock would, if there were water on the top of the core, presumably also be occupied by water, so that the inside surface would offer little resistance to movement. Cohesion between the top of the cap rock and the overlying beds would, however, also tend to hold up the cap rock. Further support to the cap rock would be given by the thicker of the folded beds of solid anhydrite in the salt, which would be left, by solution of the salt, projecting up into the brine-filled space between salt and cap rock. At the bottom of this layer of brine, on the salt, lie the crystals of anhydrite that were disseminated through the salt, mainly along the so-called "annual layers." (See figs. 1 to 4.) When the weight of the cap rock finally became too great for the forces resisting its movement, it would settle down, brecciating and grinding the projecting beds of solid anhydrite and compacting the whole mass of residual anhydrite into a breccia consisting of a matrix of anhydrite sand-partly crystals originally disseminated on the "annual layers", partly debris from the crushing of bedded anhydrite-in which the breccia fragments would be scattered and the interstices of which would be filled with brine. Within this brine the usual process of recrystallization by solution and deposition of the inclosing solid material-the anhydrite-would tend to take place, cementing the grains into a coherent rock. This periodic settling followed by cementation is assumed to be the cause of the katatectic banding. Upward movement of the salt to meet the cap rock would have the same effect, but it seems to me less 
likely that in the plastic salt, under the conditions attending the occurrence of salt stocks, this movement would take place discontinuously at short intervals.

If the process came to a stop at this point, a porous anhydrite rock with salt in the pores, like the bottom layer ( $n-n$, figs. 8 and 9 , pls. 27 and 28 ) of the specimen from the Hockley salt dome, Harris County, Tex., would result. If it continued, it must be assumed that enough time would elapse before a fresh layer of water would work its way in along the contact, to permit cementation of the preceding layer, and thus its differentiation from the next layer. Where the boundary is sharp and relatively flat there was presumably time for this cementation. Where the boundary is very irregular, as at the top of the Hockley specimen (c-c-c, fig. 8), and probably where the boundary is not sharp, the overlying layer was presumably not yet well consolidated when compaction of the layer below it took place. Some of the sharper boundaries are marked by impurities. In the Hockley specimen, for instance, the boundary $b-b$ (figs. 8, 10, and 11, pls. 27-29) has some fine-grained mineral, probably largely calcite, distributed along and adjacent to it. But the irregularity of the distribution of these grains, both longitudinally and laterally, indicates epigenetic distribution by waters penetrating along the katatectic boundary as a boundary of weakness, rather than syngenetic deposition. But whether of syngenetic or epigenetic origin in relation to the katatectic bands, this concentration of impurities on and adjacent to the katatectic surfaces indicates the presence of a definite bounding surface.

In the above presentation of the katatectic origin of the cap rock I have ascribed brecciation of anhydrite beds, freed from the salt, to crushing between cap rock and salt stock. It is quite possible that at least some of this brecciation may have taken place while the anhydrite bed was still in the salt stock, as the result of folding and flowage in the stock. ${ }^{15}$ In either case, consideration of such disturbances and changes as I have observed in anhydrite cap rock lead me to believe that most of the more extreme distortion seen in breccia fragments of primary anhydrite rock, such as is illustrated in figures $21,22,23,25$, 26 , and 27 (pls. 34-36), is due either to crushing by the descending cap rock at the time the layer containtaining the distorted fragments was formed, or to crushing within the salt stock; and not to flowage within the cap rock after its formation. That pronounced distortion can take place within the salt stock is indicated by figure 12 on page 62 of the paper by Schauberger just cited, where a $U$ bend has been produced in a fragment of an anhydrite bed in the salt.

$13 \mathrm{Ct}$. Seidl, Erich, Die permische Salzlagerstätte im Graf Moltke Schacht: Archiv für Lagerstättenforschung, Heft 10, pp. 52-54, Berlin, K. preuss. geol. Landesanstalt, 1914; Die Salzstöcke des deutschen (germanischen) und des Alpen-Permsalz Gebietes: Kali, 21. Jahrgang, especially pp. 305-306 and fig. 38, p. 304, 1927. Schauberger, O., Die Fliessstrukturen im Hallstätter Salzlager: Berg. u. IIättenm. Jahrb., vol. 79, especially pp. $57-68$, Vienna, 1931.
From the random, scattered, and rather uniform distribution of groups of strained and distorted or crushed anhydrite crystals, like those in the Hockley cap rock, illustrated in figures $12,13,14,15,16,17$, 18 , and 19 , it seems very likely that they originated as a result of settling of the cap rock while the residual anhydrite was still unconsolidated.

In the above presentation I have also spoken of the cap rock as if it were a rigid disk that settled onto the underlying salt only as a whole, without bending or breaking beforehand. The following simple calculations made with the help of P. G. Nutting, physicist of the United States Geological Survey, show that it would, however, bend and possibly break of its own weight before it settled as a whole.

The yield of a disk under uniform load is expressed roughly by the formula ${ }^{16}$

in which

$$
T=3 / 2(1-\lambda) R\left(\frac{r}{d}\right)^{2}
$$

$$
\begin{aligned}
T & =\text { horizontal unit stress. } \\
\lambda & =\text { lateral contraction. } \\
d & =\text { thickness of disk, in feet. } \\
r & =\text { clear radius of disk, in feet. } \\
R & =\text { pressure, in pounds to the square inch. }
\end{aligned}
$$

$T$ may be taken as 900 pounds to the square inch at rupture, by estimation from the value of that quantity for various other related rocks; $\lambda$ as $1 / 3$, as a rough approximation; $d$ as 800 , as for the Sulphur salt dome; $r$ as 1,100 , as for the Sulphur salt dome. ${ }^{17}$ Then

$$
\begin{aligned}
900 & =R\left(\frac{1,100}{800}\right)^{2} \\
R & =\text { roughly } 450 .
\end{aligned}
$$

With $T$ equal to the unit stress at rupture, $R$ becomes equal to the pressure at rupture.

Rough determinations on cores from the Sulphur salt dome give 1.31 pounds as the weight of a column of anhydrite 1 foot long and 1 square inch in cross section, and 1.118 pounds as the weight of a like column of gypsum. If 1.25 pounds is taken as the average weight of such a column anywhere in the cap rock the pressure of the 800-foot thickness of cap rock on its own base is 1,000 pounds to the square inch, which is greater than the value obtained for $R$, the pressure required to produce rupture, and the cap rock of the Sulphur salt dome would therefore be likely to break if unsupported on its entire base. Faults or evidences of faults have been encountered at several levels in the continuous diamond-drill core from this cap rock, and some of these may be due to breaking of the cap rock under its own weight. As many anhydrite caps have a greater diameter than that of the Sulphur salt dome they would be still more

16 Merriam, Mansfield, Mechanics of materials, 11th ed., p. 410, New York, John Wiley \& Sons, 1910.

" See Kelley, P. K., The Sulphur salt dome, Louisiana, in DeGolyer, E. L., and others, op. cit., fig. 3 , facing p. 456. 
likely to break. In any case, however, before breaking, the cap rock would yield by bending and would probably come to rest on the salt near the center of the stock and perhaps at other places. Whether the result of bending or of breaking, a few such contacts, by decreasing the length of the unsupported portions, would be likely to leave these able to support themselves. That such contacts are not common is indicated by the absence, as explained on page 91 , of tangencies or unconformities of the katatectic bands in all the specimens of anhydrite cap rock I have studied.

The pockety occurrence of anhydrite sand on top of the salt on the Winnfield dome, mentioned on page 92 , may illustrate the results of local settling of the anhydrite cap rock by bending or breaking.

CONSIDERATIONS AND EVIDENCE IN SUPPORT OF THE HYPOTHESIS OF ORIGIN BY RESIDUAL ACCUMULATION

EVIDENCE FROM THE BRECCIA FRAGMENTS

SEDIMENTARY ORIGIN OF THE BRECCIA FRAGMENTS

Figure 28 (pl. 37) illustrates an excellent example of the clasts of dense white fine-grained anhydrite with thin parallel dark bands, which I regard as fragments of an original bed of sedimentary anhydrite reworked into the cap rock. The thin section in figure 30 (pl. 37) adds nothing essential to the macroscopic evidence. It shows nondescript dark granular impurities in rather irregular lines. The exact location of this thin section, unfortunately, is not known, but the coarser anhydrite in figure 30 may undoubtedly be taken to be matrix or else recrystallized clast. If that is eliminated, there are no clear textural differences between bands. A slightly different type of banded breccia fragment is illustrated in figures 29 (pl. 37), 31 , and 32 (pl. 38). Still more distinct sedimentary stratification in a breccia fragment is illustrated in figures 26 and 27 (pl. 36). Here the banding, regarded as stratification, in fragments like $a$ and $e$, is thin, sharp, and parallel and involves distinct color differences Here, also, the boundaries are angular and sharp and leave little room to doubt that these are distinct clasts, not merely portions of the rock differentiated from their matrix by recrystallization of that matrix. The thin section (figs. 33 and 34, pl. 39) again adds little to the macroscopic evidence, except to bring out the distinct difference in grain between clast and matrix.

In the earlier paper ${ }^{18} \mathrm{I}$ used the distribution and character of carbonates in a fine-grained breccia fragment, in a specimen of anhydrite rock of unknown origin, to support the interpretation of these clasts as of primary sedimentary origin. That evidence has, I still think, a good deal of validity, although from what I have since seen of the penetration of impurities

13 Goldman, M. I., op. cit., 1925, pp. 56-64; 1926, pp. 67-72, figs. 20, 21. along any boundary of weakness, such as a bedding surface would afford, and of the tendency of waters entering along surfaces of weakness to penetrate the adjacent rock unsymmetrically, in general probably upward rather than downward, I have become a little less sure of it. Moreover, I think that the identification of the carbonates in the clasts as dolomite rather than calcite should be accepted with reservation, inasmuch as it was based on their rhombic form, which is a fairly good indication but not conclusive proof. I would rather rest the case for the sedimentary origin of the fine-grained clasts on the macroscopic characters, which seem to me quite adequate in themselves.

\section{PRIMARY KATATECTIC CAP ROCK}

Once it is clearly recognized from specimens like those illustrated in figures 28 and 29 (pl. 37) and 26 and 27 (pl. 36), in which the character and differentiation of the two main constituents are sharply defined, that anhydrite cap rock consists essentially of breccia fragments of sedimentary anhydrite, generally fine-grained, dense, and light-colored, many of them distorted, in a matrix of coarser-grained, darker anhydrite, the same two constituents can be recognized in other specimens in which their character and differentiation is less distinct. Such specimens are illustrated in figures 22 (pl. 34), 24 and 25 (pl. 35), and 35 and 36 (pl. 40).

This, according to the interpretation I am offering, is the original cap rock as it is formed by residual accumulation-the "primary" cap rock. This cap rock as it is first formed undergoes various modifications - such as gypsification-which are undoubtedly secondary, and various departures from this type, also believed to be secondary, appear within the cap rock. Even though conclusive differentiation of primary and secondary characters of the cap rock may not in all cases be possible, it is, nevertheless, very desirable in discussion to differentiate this primary type from various deviations from it that are encountered in studying cap rock. But this "primary" cap rock contains the breccia fragments of sedimentary anhydrite, which in another sense are also "primary", and there is, therefore, the necessity of differentiating between two "primary" rocks. To bring out clearly and to emphasize this difference, and to differentiate between sedimentary and residual cap rock, I propose to call the breccia fragments "primary sedimentary breccia fragments or clasts" and the type of cap rock just defined "primary katatectic cap rock".

\section{THREE HYPOTHESES OF BRECCIATION}

Three possible interpretations of these breccia fragments have been considered in their bearing on the origin of the cap rock and will be discussed here. 
All of them are based on the acceptance of the hypothesis of the primary sedimentary origin of the clasts. An intraformational sedimentary breccia.-One interpretation is that the breccia originated as an intraformational conglomerate or breccia, or what the British, in describing certain limestones, call penecontemporaneous breccia - that is to say, that the clasts were formed by brecciation of a bed of anhydrite before deposition of the next overlying bed. But if the breccia fragments were formed in that way there should be present in the cap rock, and rather abundantly one would expect, conformable included layers of this dense white anhydrite rock, in part at least with the closely spaced thin dark partings. The fact that I have found such layers nowhere in cap rock, and that, as far as I can judge, all the cap rock where unaltered is of the coarse-grained dark type, generally with breccia fragments-the type I have called primary katatectic cap rock-practically eliminates that interpretation of the origin of the breccia, and, with it, the interpretation of the cap rock, in its present condition, as an original bed of sedimentary anhydrite.

A brecciated overlying bed or a residual breccia.The other two interpretations of the origin of the breccia that I have considered are that it resulted from brecciation, during upward movement of the salt stock, of a bed of sedimentary anhydrite overlying the salt in its original bedded position; or that it is the result either of brecciation by flowage - within the salt stock-of included beds of anhydrite, or of crushing - between the top of the salt stock and the overlying cap rock-of anhydrite residual from the solution of the salt stock.

I shall try to show, in discussing the katatectic surfaces, that they afford a means of differentiating between these two interpretations; but in the breccia itself there is little evidence on which such a differentiation can be based.

Only two characteristics of the breccia itself seem to fit the residual origin of the cap rock better than its sedimentary origin. One of these is the size of the breccia fragments. It seems likely that brecciation of an overlying bed of anhydrite as a whole by the upward push of a salt stock a mile or two in diameter through the midst of tightly enclosing sediments would yield at least a great many large fragments, some the full thickness of the bed and many feet in length. If that were the case, coring of the cap rock should yield long continuous sections of well-bedded, primary sedimentary anhydrite. Such material I have never seen. Some of the largest fragments of apparently primary anbydrite that $I$ have noted are illustrated in figures 20,21 , and 23 (pl. 34). Their dimensions are not within the range suggested above. The objection might be raised that the assumption of large fragments implies only a single brecciation, but that if there were one, there is no obvious reason for not expecting several. That brings me to the second consideration which somewhat favors the residual origin. If there were several such periods of brecciation, one would expect to find not merely clasts of primary sedimentary anhydrite in dark matrix anhydrite but breccia fragments of breccia - that is, primary clasts and matrix, very probably showing katatectic banding-in a later matrix from which they could be differentiated. I have seen nothing in which $I$ can recognize a trace of that structure. It might be suggested that recrystallization, of which there has undoubtedly been a great deal in the cap rock, would weaken the evidences of repeated brecciation; but in that case it could hardly leave such distinct proof of one brecciation and none of any others.

THE PARALLEL BANDS (KATATECTIC BANDS) EXAMPLES OF KATATECTIC BANDING

Two of the best examples of katatectic banding are illustrated in figures 37 (pl. 40) and 8 (pl. 27), the latter from the contact of anhydrite cap and salt in the shaft at Hockley. Figures 24 and 25 (pl. 35) are good examples of more average occurrences and show more of the general relations. I have not had the opportunity to make a continuous study of the section of any cap rock. The diamond-drill core through the gypsum-anhydrite cap rock in well 194 of the Union Sulphur Co., which has formed the principal material for my study of gypsum-anhydrite cap rock, had to be discarded for lack of space in which to store it, after a range of specimens assumed to represent it adequately had been selected. It has therefore not been possible to follow up various problems that were developed by the study of the pieces of core selected and that required the study of intervening portions of the core. But the common occurrence of katatectic banding in specimens of anhydrite cap rock from various other salt domes, as well as from the Sulphur dome, leads at least to the conclusion that the cause, whatever it may be, is widespread and characteristic.

\section{HYPOTHESES OF ORIGIN OF KATATECTIC BANDING}

Three alternative hypotheses to account for the origin of the katatectic bands have been considered. One is that they are original strata of a bed of sedimentary anhydrite which overlay the salt. Another is that they originated as a result of periodicity in the process of accumulation of the cap rock as a residue from the solution of the top of the salt core-the process on which the term "katatectic" is based. The third hypothesis is that they are the result of shearing in the cap rock.

The hypothesis of their origin by some process of diffusion as suggested in my earlier paper ${ }^{19}$ seems untenable in view of the fact that the dividing surfaces mark zones of mechanical weakness along which water probably circulated more freely and along which slight movements have taken place. Besides, to produce such straight and parallel bands, diffusion would, it

${ }^{9}$ Goldman, M. I., op. cit., 1925 , pp. 56, 59; 1926, pp. $64,66$. 
seems probable, have to act in a homogeneous medium. The cap rock, with its inclusions of fine-grained primary anhydrite rock clasts in a coarser matrix and with other differences of texture and grain, is far from being such a homogeneous medium. Finally, if the bands were formed by diffusion, some of them should cut through the clasts. This I have not seen in any specimen examined.

The hypothesis that they are strata in a bed of sedimentary anhydrite requires the assumption that the breccia of dense white primary anhydrite fragments is intraformational. I have presented above (p. 89) the evidence against that hypothesis.

The differentiation between the other two methods of origin is of fundamental importance, for unless the origin of the katatectic banding by residual accumulation can be demonstrated there is no conclusive evidence in the cap rock itself of its residual origin. If the surfaces called katatectic are due to shearing, the breccia, as far as conclusive internal petrographic evidence goes, might have originated by the brecciation of a bed of anhydrite overlying the salt of the stock as well as by residual accumulation, and the only evidence in support of residual origin is that of the general geologic relations.

\section{CONSIDERATIONS AND EVIDENCE IN SUPPORT OF THE ORIGIN OF KATATECTIC BANDING, AND OF THE ANHY- DRITE CAP ROCK IN GENERAL, BY RESIDUAL ACCU- MULATION}

PROBABILITY OF PERIODICITY IN RESIDUAL ACCOMULATION

I am not prepared to go into a general philosophic discussion of periodic processes in nature. It is, however, probably safe to say that periodicity in natural processes is the rule rather than the exception.

Movements along faults are now generally believed to take place spasmodically, and the settling of the cap rock would be a somewhat similar process. On the other hand, sediments showing no recognizable results of periodicity in their formation are certainly known. There would thus be no basis for asserting that all geologic processes are recognizably periodic and that, therefore, periodicity in the katatectic formation of cap rocks, such as would result in the observed banding, is to be expected-that the katatectic surfaces are due to periodicity in the residual accumulation of the cap rock and are therefore evidence of its origin by that process. It is safe to say, however, that periodicity and banding in the residual process are rather likely and that the occurrence of the katatectic bands is therefore not inconsistent with this hypothesis of the origin of the cap rock.

There is a specific consideration that favors the conclusion that there must have been periodicity in the formation of cap rocks containing breccia fragments of primary sedimentary anhydrite. As explained above (p. 84), it is assumed that the salt table cuts across folded beds in the salt stock in which steeply dipping beds of anhydrite are included, as illustrated in figures 42 to 44 (pl. 41). As the salt table is lowered by solution the upper ends of these beds are left projecting above it. At the same time anhydrite disseminated along the "annual layers" in the salt stock is freed by solution and gathers as a layer on the salt table. The overlying cap rock in settling is supposed to crush the projecting ends of the anhydrite beds, whose fragments mingle with the anhydrite sand. It is assumed that these are the breccia fragments found in the cap rock formed by consolidation of the sand. It is the size of these breccia fragments that is taken as evidence of a certain periodicity in the formation of the cap rock. If the cap rock descended continuously as the salt table was lowered, the projecting ends of the beds of anhydrite would be crushed as fast as they were freed by solution, and only a fine powder would result. To yield the fragments, some of them a few inches in diameter, that are encountered in the cap rock, it seems necessary that descent of the cap rock should halt at intervals, during which larger portions of the anhydrite beds would come to project above the descending salt table, so that when they were finally crushed they would yield these larger fragments.

Considerable thicknesses of anhydrite cap rock with little or no recognizable katatectic banding might be due to variations in the length of periods rather than to the absence of periodicity. Such variations could, for instance, be caused by differences in the thickness and strength of beds of anhydrite at different levels of the salt core. These differences might be syngenetic in the anhydrite bed or might be induced by the folding of the salt core. ${ }^{20}$ A thick solid bed of anhydrite would give the cap rock more support and thus cause the formation of a thicker katatectic band. The fact that considerable thicknesses of anhydrite cap rock with little or no recognizable katatectic banding contain unusually abundant clasts of primary anhydrite rock (as illustrated, for instance, in the upper two-thirds of figs. $24, \mathrm{pl} .35$; in parts of fig. 25 , pl. 35 ; and in fig. 35 and 36, pl. 40 ) may be regarded as supporting this interpretation.

On the other hand, katatectic surfaces undoubtedly favor the penetration of water and as a consequence the recrystallization of the cap rock above them, so that the greater scarcity of primary anhydrite clasts above the katatectic surfaces in more closely banded cap rock, as in the more closely banded parts of the specimens illustrated in figures 24,25 , and 36 , may be a secondary character.

If the difference in the abundance of clasts of primary sedimentary anhydrite in banded and unbanded cap rock is mainly secondary and due to the disappearance

:0 Cf. Seidl, Erich, Die permische Salzlagerstătte im Graf Moltke Schacht: Arehiv für Lagerstättenforschung, Heft 10, Preuss. geol. Landesanstalt, 1914, especially pp. 52-54 and the colored plates at the back of the volume, showing variations in the thickness of an anhydrite bed as a result of folding. 
of the clasts by recrystallization, the wide spacing of katatectic surfaces in specimens like those illustrated in figures 24,25 , and 36 may be due to the fact that for lack of time or for some other reason cementation did not take place between the settling movements of the cap rock. This view is supported by the fact that vague traces of banding can be seen even in the upper part of the specimen shown in figure 24.

\section{DIFFERENCES FROM SHEAR SURFACES}

There is no doubt that there has been movement along many of the katatectic surfaces, but the amount of movement indicated by crushing along them is very slight and little in excess of the various other internal movements in the rock adjacent to them. As these surfaces are boundaries of weakness, the crushing along them cannot be taken as evidence of their origin by shearing.

On the other hand, it must be realized that in view of the undoubtedly large amount of recrystallization in the cap rock the present grain of the rock adjacent to the katatectic surfaces is not conclusive evidence as to changes that may have taken place along these surfaces in the past. But the fact that intense mylonitization has occurred throughout the cap rock and that I have found only the slightest evidence of mylonitization along the katatectic surfaces makes it improbable that more intense mylonitization ever took place along them. On that question also the evidence from the basal cap rock in the Hockley shaft (figs. 8 to 19 , pls. 27 to 33 ) is significant. Some of the characters of this specimen may, therefore, first be pointed out in somewhat more detail.

The katatectic surfaces seen in the polished face (fig. 8, pl. 27) are for the most part roughly flat, roughly horizontal, and roughly parallel, but they are not entirely so. They also exhibit a great range in sharpness of definition, some being sharper than others, and even different parts of the same boundary differing in sharpness. The lowest band is an intergrowth of salt and anhydrite. (See fig. 9, pl. 28.) Its upper boundary also varies in sharpness of definition. The uppermost katatectic surface included in the specimen $(c-c-c$, fig. 8$)$ is both vague and unusually irregular.

Under the microscope the anhydrite crystals are seen to be on the whole fairly uniform in size, but scattered among the dominant size, as illustrated in figures 12 and 13 (pl. 30), 16 and 17 (pl. 32), and 18 and 19 (pl. 33), are small patches of finer material. Strain is common in the larger crystals. The material has undoubtedly been subjected to some stress, and the fine portions are the result of crushing. On the katatectic surfaces, however, as illustrated in figures 12 and 13 and figures 18 and 19, the amount of excess crushing is trivial.

In my earlier paper I presented evidence against the assumption that relatively flat, parallel surfaces, spaced like these are the result of shearing. Further observation, especially of specimens from the continuous diamond-drill core from the gypsum-anhydrite cap rock of the Sulphur salt dome, has tended to confirm this conclusion. In the earlier paper considerations were presented for expecting shearing to produce lenticular structure - that is, converging surfaces. Such structure is illustrated by a specimen like that shown in figure 40 (pl. 41), in which, in spite of pronounced parallelism, there is a distinct lenticular structure. The specimen illustrated in figure 41 (pl. 41) shows, parallel to a vague curving, flowlike, lenticular structure, a curved surface of parting, presumably produced by a shearing stress. The katatectic surfaces, on the other hand, are dominantly flat and parallel. Such departures from flatness as they show are irregular and unsystematic. As pointed out above (p. 88), local sagging of the cap rock is likely to result in some converging katatectic surfaces, and possible irregularities in the salt table - the top surface of the salt stock would tend to have the same effect; but in very few of the several hundred specimens studied was even a well-defined tendency to convergence of katatectic surfaces noted. Three of these are illustrated in figures 37,38 , and 39 (pl. 40). In the specimen shown in figure 37 the thinness of the bands is the main cause of the appearance of greater convergence in their boundaries, but even there no two katatectic surfaces can be seen definitely to meet. The characters of specimens adjacent to the specimen shown in figure 39 indicate that it is very near a fault or some similar disturbance which has undoubtedly affected the lower part of the specimen, including the katatectic surface in it. The specimen shown in figure 38 is also within a few feet of a disturbed zone.

The usually wide spacing of the katatectic surfaces, running around 1 to 2 centimeters, also does not seem to be a character that would result from shearing.

I have pointed out that in general the lack of evidence of pronounced crushing along the katatectic surfaces could not be accepted as disproof of their origin by shearing, because recrystallization might have effaced such evidence. This qualification does not, however, seem to me to have much force with reference to the specimen from the contact with the salt at Hockley (fig. 8, pl. 27). There might have been recrystallization along the upper katatectic surfaces in that specimen, but it is not likely that recrystallization could have taken place along the lowest of those surfaces (a-a, figs. $8,9,12$, and 13) and yet have left the lowermost band ( $n-n$, figs. 8 and 9 ; cf. fig. 12) the intergrowth of salt and anhydrite that it is at present.

It would, furthermore, be difficult to conceive of any force connected with a salt dome that would be able to produce such horizontal surfaces in this position by shearing. Horizontal shear surfaces can be produced by lateral yielding of a horizontal mass to 
SHORTER CONTRIBUTIONS TO GENERAL GEOLOGY, 1932-33

vertical pressure, ${ }^{21}$ but they are not likely to be widely but regularly spaced and parallel, like those illustrated in figure 8 (pl. 27), nor so near the surface along which the pressure was applied.

Finally, the irregularity of some of the katatectic surfaces, such as the topmost one $(c-c-c)$ in the Hockley specimen shown in figure 8 , could not conceivably result from shearing.

\section{THE SALT TABLE}

The fundamental significance of the salt table in relation to the origin of anhydrite cap rock has been discussed in the introduction.

\section{THE CONTACT OF SALT AND ANHYDRITE}

I am indebted to Mr. L. P. Teas, ${ }^{22}$ of the Humble Oil \& Refining Co., of Houston, Tex., for detailed information about the contact of anhydrite cap and salt in shafts on the Grand Saline salt dome, Van Zandt County, Tex., and the Winnfield salt dome, Winn Parish, La.

On the Grand Saline salt dome the contact was at a depth of about 130 feet, and 4 or 5 inches of anhydrite sand with included brine are reported. The brine was under considerable pressure.

On the Winnfield salt dome, likewise, 3 to 4 inches of anhydrite sand are reported as present at the contact, which was at a depth of 438 feet. Here, also, there was water under considerable pressure (220 pounds to the square inch, corresponding to the weight of a column of water about 508 feet high, 70 feet more than the distance to the surface). At this contact the anhydrite is said apparently to have been in pockets, for it was found only over an area 4 feet square. The possibility of the localization of solution and residual accumulation in this way on the top of a salt dome as the result of control by fissures in the overlying rock has been considered in my paper on Clay Creek. ${ }^{23}$ Irregular sagging of the cap rock as discussed above (pp. 87-88) or irregularities in the top surface of the salt might also cause such localization. The area to which residual anhydrite sand is said to be restricted on this stock, however, seems rather small. In view of the difficulty of making satisfactory observations in the bottom of a shaft in the presence of water under considerable pressure, it seems best, for the present, to accept this record with reservations.

It is worth noting that the flow of water under pressure at both these contacts fits well with the conclusion reached in my paper on Clay Creek, ${ }^{24}$ that the formation of the flat salt table is probably to be ascribed to some more permeable bed, a "water sand".

These occurrences of anhydrite sand and water at the contact of salt and anhydrite cap rock, if they are

21 Cf. Cloos, Hans, Bau und Bewegung der Gebirge, fig. 6, p. 260, Berlin, Gebrüder Borntraeger, 1928.

22 Letter of June 18, 1931.

${ }^{23}$ Goldman, M. I., op. cit. (1931), p. 1112.

2) Idem, p. 1112. thought of in terms not of a static condition but of geologic processes in geologic time, seem to point pretty clearly to residual accumulation of anhydrite cap rock. Even if there is no circulation of water, solution by diffusion is almost certain. The residual anhydrite is there in the form of an anhydrite sand, as is to be expected, and, if allowance is made for compaction by settling of the cap rock, even the thickness of the space and of the sand layer conforms to the average thickness of katatectic bands.

This layer of brine between anhydrite cap rock and salt has not been encountered on all salt domes. I have discussed elsewhere ${ }^{25}$ the problem of its presence or absence.

In view of the foregoing observations, the salt table establishes a strong probability in favor of residual accumulation of anhydrite cap rock. As stated above (p. 85), even if a bed of anhydrite overlying the salt in depth were brought up on top of the salt stock, the probability that anhydrite would be added to it by residual accumulation beneath it, on those salt stocks which have a salt table, would make improbable the presence on them of a cap rock derived purely from such an overlying bed.

PROBABLE RELATION OF AN OVERLYING BED OF ANHYDRITE TO SALT AFTER FLOWAGE OF THE SALT

If the steps in the upward progress of a bed of salt changing to a salt stock are visualized, it is difficult to conceive of the formation of an anhydrite cap containing breccia fragments, even from an overlying bed of anhydrite, without the intervention of solution. For, if a substance as plastic as salt were to brecciate overlying or surrounding beds, it is hard to believe that it would not penetrate and engulf the breccia. According to Seidl ${ }^{26}$ something of that kind kas taken place in the Alps and under the old miners' name "Hazelgebirge" (hazel-nut formation) is described and illustrated by him. Schauberger, ${ }^{27}$ however, does not share this interpretation; he considers the "Hazelgebirge" to be the product of flowage in a bed of salt which originally contained as thin interbedded layers the material of the breccia now found in it. In Seidl's figure 58 the inclusion of fragments of an overlying anhydrite bed in salt that has broken through it is photographically illustrated. But the conditions in that occurrence are not quite like those considered in this paper, because there the anhydrite bed was also overlain by salt. It should be noted in passing that a corollary of this assumption seems to be that if there was not a bed of anhydrite directly overlying the salt, then whatever beds did overlie the salt, especially the more brittle among them, should, before the formation of cap rock by solution, have yielded a breccia to be included in

${ }^{25}$ Idem, p. 1111.

${ }^{26}$ Seidl, Erich, Die Salzstöcke des deutsehen (germanischen) und des AlpenPermsalz-Gebietes: Kali, Jahrgang 21, especially pp. 305-306, 1927.

${ }^{27}$ Schauberger, O., Die Fliessstrukturen im Hallstätter Salzlager: Berg- u. hüttenm. Jahrb., vol. 79 , pp. 27-38, 57-78, 82-89, 1931. 
the outer parts of the salt, and that when solution of the salt did begin, these breccia fragments should have accumulated as an outermost layer, cemented or uncemented according to circumstances, above the anhydrite cap on top and outside it on the flanks. Is there any evidence of such an occurrence known from American salt domes? In my earlier paper ${ }^{28} \mathrm{I}$ suggested that some of the sedimentary material of the calcite cap (more correctly, probably, the false cap ${ }^{29}$ ) might be such material brought up from depth. The suggestion still seems valid, though I would no longer regard the occurrence of this sedimentary material as proof of the primary sedimentary origin of the anhydrite cap. Some breccias above salt, such as that from Hockley illustrated in figures 45 and 46 (pl. 42), might also represent this material.

If this argument is well founded, it confirms the conclusion arrived at above that the anhydrite cap rock can not be an original bed of sedimentary anhydrite. It seems, also, that in that case there would be no essential difference, in such characteristics as have hitherto been recognized in it, whether it had been derived from an overlying bed of anhydrite or from included anhydrite beds and disseminated crystals. It might be that there would be differences in such features as the size, shape, and distortion of the breccia fragments, but, so far as I know, the basis for discriminating such differences is not now available.

\section{VARIATIONS IN THICKNESS OF CAP ROCK}

There is evidence that the cap rock above the salt table varies in thickness and is most commonly thickest toward the center, but, as mentioned on page 86 , the information about cap rock is so often extrapolated that it becomes difficult to find satisfactory samples. There is perhaps none published about American salt domes more satisfactory than that contained in figure 3 of Applin's paper on Stratton Ridge. ${ }^{30}$ In addition to the variation in thickness above the salt table there is the pronounced thinning on the flanks, which may be regarded as merely an extension of the thinning toward the edges above the salt table. Irregular variations in thickness in general may, it seems to me, be much more readily accounted for by the hypothesis of residual accumulation than by that of an original sedimentary bed, because anhydrite would be likely to be irregularly distributed in the folds of a salt stock (see figs. 42 and 43 , pl. 41 , and pp. 85-86), and the decapitation of such a stock by solution would therefore leave various thicknesses of residual anhydrite in different parts. Thickening toward the center fits in well with the residual theory, because, in the upward progress of the salt stock,

${ }^{29}$ Goldman, M. I., op. cit., 1925, pp. 72-74; 1926, pp. 80-87.

${ }_{29}$ Brown, L. S., Cap-rock petrography: Am. Assoc. Petroleum Geologists Bull., vol. 15, No. 5, pp. 510 (false cap), 511 (calcite cap), 1931. Goldman, M. I, op. cit. 1925, pp. 68-74; 1926, pp. 76-82

30 Applin, P. L., in DeGolyer, E. L., and others, op. cit., p. 654 friction of the surrounding sediments would presumably retard the outer parts, so that $(a)$ flow would tend to be more rapid toward the center, $(b)$ in the formation of a flat salt table the greatest amount of solution would therefore be present there, and hence, $(c)$ other things being equal, the thickest accumulation of residual anhydrite would occur toward the center.

\section{PRESENCE OR ABSENCE OF CAP ROCK}

No hypothesis of the origin of gypsum-anhydrite cap rock is satisfactory which cannot be made to account for the absence of this cap rock on certain domes. Various possible explanations of this condition, on the basis of the hypothesis of sedimentary origin, were offered in my earlier paper. ${ }^{31}$ It seems easier to explain under that hypothesis than under the hypothesis of residual origin. Information on this topic is not readily enough available to permit a satisfactory analysis. One of the suggestions offered in the earlier paper, however, seems still to have a good deal in its favor. That is, that where cap rock is absent, solution may have been so active that calcium sulphate as well as salt may have been dissolved.

As the following figures ${ }^{32}$ show anhydrite is, after all, rather soluble and gypsum much more so.

At a temperature of $10^{\circ} \mathrm{C}$, 0.19 gram of gypsum is dissolved per 100 cubic centimeters of water; at $40^{\circ} \mathrm{C}$., $0.21 \mathrm{gram}$; at $100^{\circ} \mathrm{C}$., $0.16 \mathrm{gram}$. The solubility of gypsum thus reaches a maximum around $35^{\circ}$ to $40^{\circ} \mathrm{C}$. At $100^{\circ} \mathrm{C}$., 0.0626 gram of anhydrite is dissolved per 100 cubic centimeters of water. No other figures for anhydrite were found.

In salt solution the solubility of gypsum is much greater, and this is of course significant, as residual separation of anhydrite or gypsum on top of a salt stock would take place in water saturated or nearly saturated with salt. The solubility of calcium sulphate (presumably gypsum) in a brine containing 32.05 grams of $\mathrm{NaCl}$ per 100 cubic centimeters at $26^{\circ} \mathrm{C}$. (a saturated solution of $\mathrm{NaCl}$ at $25^{\circ} \mathrm{C}$. contains about 36 grams per 100 grams of water $)^{33}$ is 0.572 gram of calcium sulphate per 100 cubic centimeters of brine ${ }^{34}$

In the paper on Clay Creek ${ }^{35}$ I have referred to evidence indicating more active solution above a depth of 2,000 feet than below that depth. Gypsum is the stable form of calcium sulphate in the presence of water down to depths of a few hundred feet. Newland ${ }^{36}$ says that anhydrite is probably the stable form of calcium sulphate below 200 to 300 feet, and Udden ${ }^{37}$ reports gypsum to a depth of 850 feet.

31 Goldman, M. I., op. cit., 1925, Np. 67-68; 1926, pp. 75-76.

${ }^{32}$ Seidell, A., Solubilities of inorganic and organic compounds, 2d ed., p. 214 New York, Van Nostrand, 1919.

${ }^{33}$ Idem, p. 640

31 Idem, p. 218

35 Goldman, M. I., op. cit. (1931), pp. 1105-1113.

${ }^{36}$ Newland, D. H., Ceology of gypsum and anhydrite: Econ. Geology, vol. 16, p. $394,1921$.

${ }^{37}$ Udden, J. A., Laminated anhydrite in Texas: Geol. Soc. America Bull., vol. 35, p. 348,1924 . 
In the earlier paper ${ }^{38} \mathrm{I}$ referred to the effect of salt in solution in lowering the temperature at which the transformation of anhydrite to gypsum is possible. Under geologic conditions the dehydration of gypsum and its conversion back to anhydrite is probably slow, so that the mere presence of gypsum at a certain depth is not proof that it is stable at that depth. A large amount of evidence, carefully controlled geologically and petrographically, will be needed to permit more exact determination of the depth at which gypsum is stable under given conditions. But, in any case, at the lesser depths at which there is reason for believing that more water is available for dissolving the salt of salt stocks, gypsum - the more soluble form of calcium sulphate -is also more likely to occur. We might, therefore, expect to find cap rock absent more frequently on shallow salt stocks than on deeper ones. The scarcity or absence of gypsum-anhydrite cap rock on the Five Islands salt stocks, ${ }^{39}$ except Belle Isle, where it is very incomplete, fits this suggestion. On Jefferson Island, Vaughan reports 18 to 24 inches of "limestone" [calcite] cap rock ${ }^{40}$ in only a few of the holes drilled to the salt. On Côte Blanche he records "only small lentils of cap rock from a few inches up to 4 feet in thickness" ${ }^{41}$ and does not state whether they are calcium carbonate or calcium sulphate. At Belle Ile "590 feet of gypsum, anhydrite, and sulphur" ${ }^{42}$ are reported immediately above the salt in one hole, but other drill holes encountered little or none. Vaughan's figure $12^{43}$ gives cross sections showing the very irregular distribution of the cap rock on this dome. On the Weeks and Avery Island salt stocks no cap rock is reported.

As I have seen them, the salt stocks of the Five Islands have another character which might help to explain the absence of cap rock on most of themnamely, that they do not appear to contain beds of sedimentary anhydrite rock. It may be that where

35 Goldman, M. I., op. cit., 1925, p. 77; 1926, p. 85.

${ }^{3}$ Cf. Vaughan, F. E., The Five Islands, Louisiana, in DeGolyer, E. L., and others, ols. cit., pp. 356-397.

10 Idem, p. 360

1. Idem, p. 383

12 Idem, p. 388.

13 Idem, p. 391 such beds are absent the disseminated anhydrite of the "annual layers" is more likely to be dissolved as fast as it is freed from the salt stock by solution of the salt.

On very young salt stocks cap rock might also be lacking, because it had not yet had time to form.

\section{ACKNOWLEDGMENTS}

I will not try to name all the individuals to whom I am indebted for material, information, or discussion that has helped me in preparing this paper. Those who have contributed specimens used as illustrations are named in connection with those illustrations. I wish here to thank all who have supplied these specimens and those who have helped in other ways. Special thanks are due to Mr. L. P. Teas, of the Humble Oil \& Refining Co., for specimens (one of which furnished important evidence for this paper) from the shaft on Hockley salt dome, and for information and discussion about the conditions encountered there and elsewhere; to Dr. Marcus A. Hanna, of the Gulf Production Co., who supplied valuable material and information for the study of the anhydrite occurring in the salt of salt stocks and very generously yielded the right to use material on which he was himself preparing to publish; to Mr. Albert G. Wolf, of the Texas Gulf Sulphur Co., whose keen interest in the scientific problems of salt domes has, I feel, been the basis of the loyal manner in which he has at all times kept my investigations in mind and sent me or directed me to especially significant material and information; to the late Dr. Sidney Powers, of the Amerada Petroleum Corporation, who gave to my investigations, as to so many others, the enthusiastic interest and cooperation which was characteristic of him, and who on many occasions supplied me with information and specimens; and finally to Dr. Donald C. Barton, of Houston, who, although he has not hitherto accepted the theory of residual origin of anhydrite cap rock on American salt domes, has been a stanch supporter of my investigations with material, information, and discussion. 


\section{PLATES 24-42}

$165472-33-3$ 


\section{PLATE 24}

FigURE 1. General view of salt from one of the Five Islands salt domes, Louisiana, containing a band of impure salt carrying disseminated anhydrite crystals. On account of the transparency and loose texture, especially of the matrix salt, and the consequent large amount of internal reflection, the photograph does not give a very correct idea of the appearance of the band in relation to the matrix. Though the boundaries of the band are not sharp, they are more straight, regular, and parallel to each other than they appear in the illustration. The specimen was selected for the sharpness and thickness of the impure band. The crystals of the matrix are very transparent and sharply defined and are so loosely attached to each other that the matrix is extremely friable. In the dark impure band the crystals are somewhat smaller and the band has much more cohesion-is, in fact, very tough. U.S.N.M. 97788 A. Natural size. Cf. figures 2 and 4 . (See pp. 84, 86.)

Figure 2. Polished face of the band of impure salt illustrated in figure 1, with specular illumination. The illustration gives some indication of the very irregular and random distribution of the anhydrite crystals, which are the small bright grains projecting above the polished surface. As this salt is of sedimentary origin and has been subjected to intense flowage, it probably was not originally in such coarse crystals as it now is. It may have recrystallized, however, without affecting the distribution of the anhydrite crystals, which was probably originally also random. The anhydrite grains have been retouched to bring them out more clearly. I.S.N.M. 97788 G. (See pp. 84, 86.) 

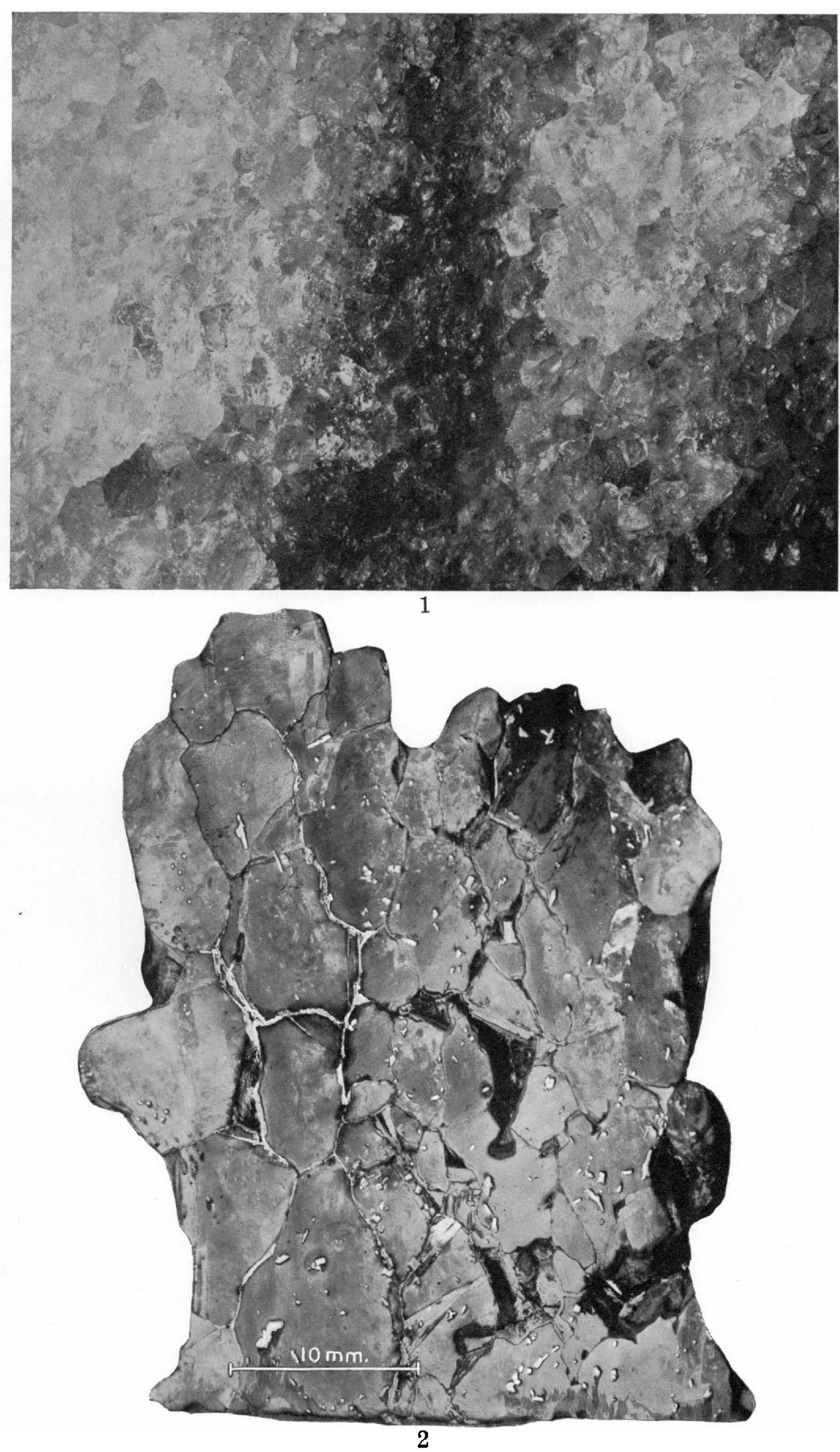

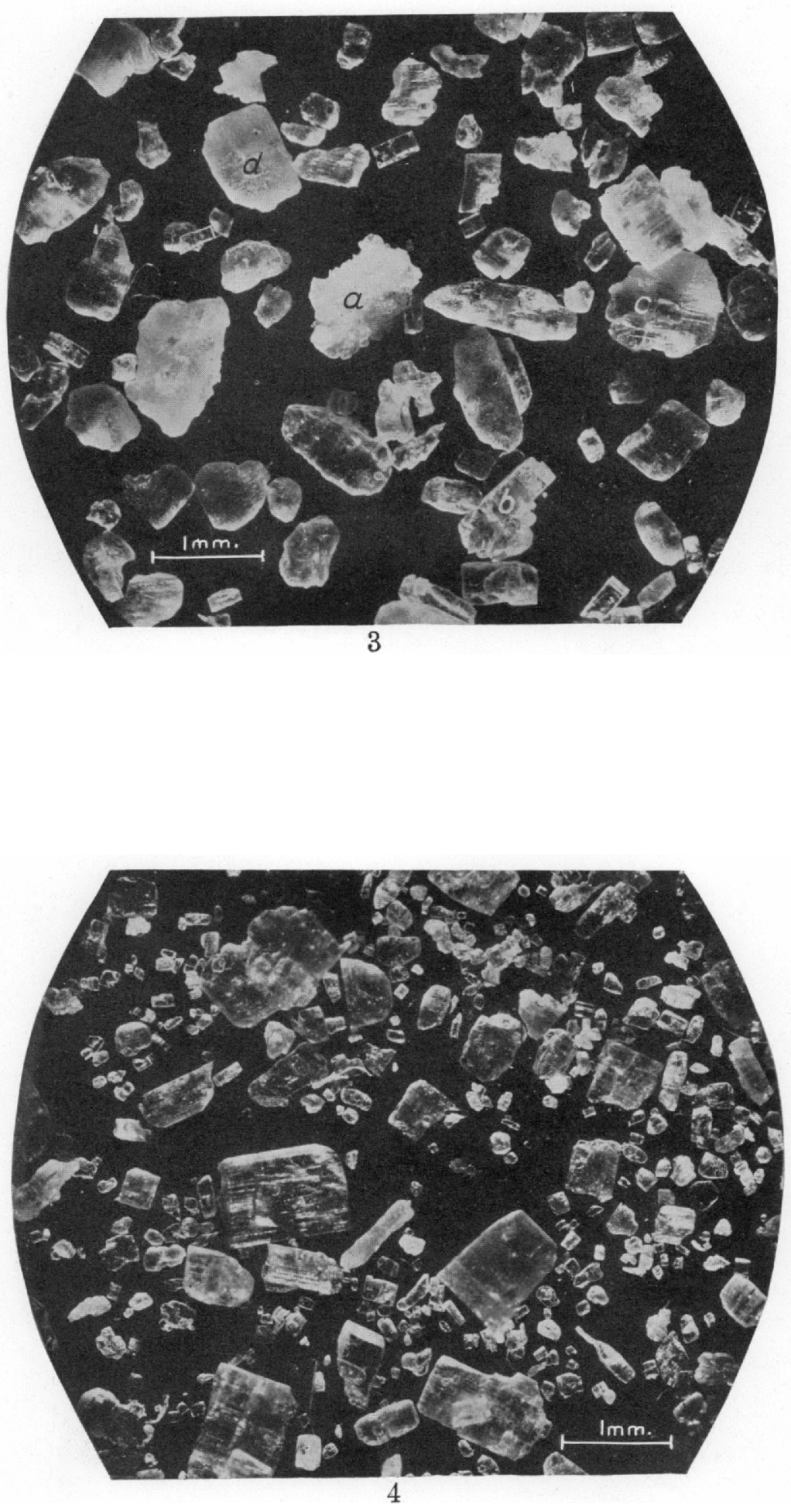


\section{PIAATE 25}

Figure 3. Anhydrite crystals residual from the solution, by water, of a sample of the impure salt about 300 feet below the top of the salt stock in the mine of the Houston Salt Co., Hockley salt dome, Harris County, Tex. The fragment $a$ at the center is made up of many small crystalline grains of anhydrite; hence its white opaque appearance. Grains of this kind, some of them as much as 1 centimeter in diameter and many of them containing small clear grains of sulphur, are common in the water insoluble residue of this salt. Comparison with figure 4 will show that these anhydrite crystals from Hockley are somewhat more rounded than those from the Five Islands salt. This may be due to more attrition during the flowage of the salt or to solution during its recrystallization. These also appear less transparent than those from the Five Islands salt. This is due to small fracture surfaces in the crystals from Hockley, an additional indication that they have been subjected to more stress. The crystals from Hockley also vary less in size, and there are fewer fine crystals among them. The illustration fails to bring out the prevalence of tabular prismatic crystals in this sample; $b$ is probably one of these on edge and $c$ and $d$, some lying on their bases. It is from material like this that, it is assumed in this paper, the cap rock illustrated in figures 8 to 19 is derived. The crystals were obtained from a specimen received from Dr. Marcus A. Hanna, of the Gulf Production Co., Houston, Tex. U.S.N.M. 97789. (See pp. 84-86.)

Figure 4. Anhydrite crystals residual from the solution, by water, of the band of impure salt from one of the Five Islands salt domes, Louisiana, illustrated in figures 1 and 2 . It is material like this that, it is assumed in this paper, forms the matrix of anhydrite cap rock. U.S.N.M. 97788 B. (See pp. 84, 86.) 


\section{PLATE 26}

Figures 5 and 6 . General views of a specimen of salt with lenses of disseminated anhydrite from depth of 2,172 feet in Fitzsimmons no. 1 well on Brenham salt dome, Washington and Austin Counties, Tex. Lenses of salt full of disseminated anhydrite crystals grade rather sharply into lenses with little or no disseminated anhydrite. The purer salt is gray; the anhydritic salt more yellowish white. Figure 5 shows the flatter face, which is probably the one Barton had in mind when making his sketch. (See p. 84.) The flat surface in what is shown as the upper part of the specimen has been ground since Barton saw it. Figure 6, taken at an angle from the left side of the specimen as seen in figure $\tilde{\mathfrak{j}}$, brings out the much greater solvent action of the water on the purer salt than on the more anhydritic salt of the specimen. Specimen obtained from Mr. Fitzsimmons, who drilled the well. U.S.N.M. 97790. Natural size. (See pp. 84, 85.)

FIGURE 7. Detail of the polished face of the specimen illustrated in figures 5 and 6 , with oblique illumination. The area shown is just to the right of the $V$-shaped reentrant that penetrates, from the left, the polished face in the upper part of the specimen, as illustrated in figure 5. The ragged and irregular left edge of the picture is the edge of the polished face here. As indicated by the presence of the $V$-shaped depression, a lens of purer salt tapers off, toward the apex of the $V$, into the more anhydritic salt of the area of the polished face. In figure 7 the end of this lens of salt appears as a larger area of salt in the center and upper left part of the picture and passes out into the more anhydritic salt surrounding it. On account of the oblique lighting, which was needed in order to obtain this picture, the surface of the salt in some of the bordering parts of the area represented, where the anhydrite crystals are more crowded, cannot be recognized. But the strong shadows cast by the anhydrite crystals there indicate that these crystals, like those in the more open and central parts of the area, project above the sof ter salt which incloses them. In general the orientation of the anhydrite crystals is random. But a magnified surface, larger than could be reproduced photographically, shows a moderate prevalence of elongation of the crystals in the direction of the elongation of the lenses of purer and of more anhydritic salt, indicating "flowage." By their size and shape and the integrity of their crystal outlines, these anhydrite crystals indicate that they are of the disseminated type which forms the matrix of cap rock, and not products of the crushing of primary sedimentary anhydrite rock. (See pp. 84, 85.) 

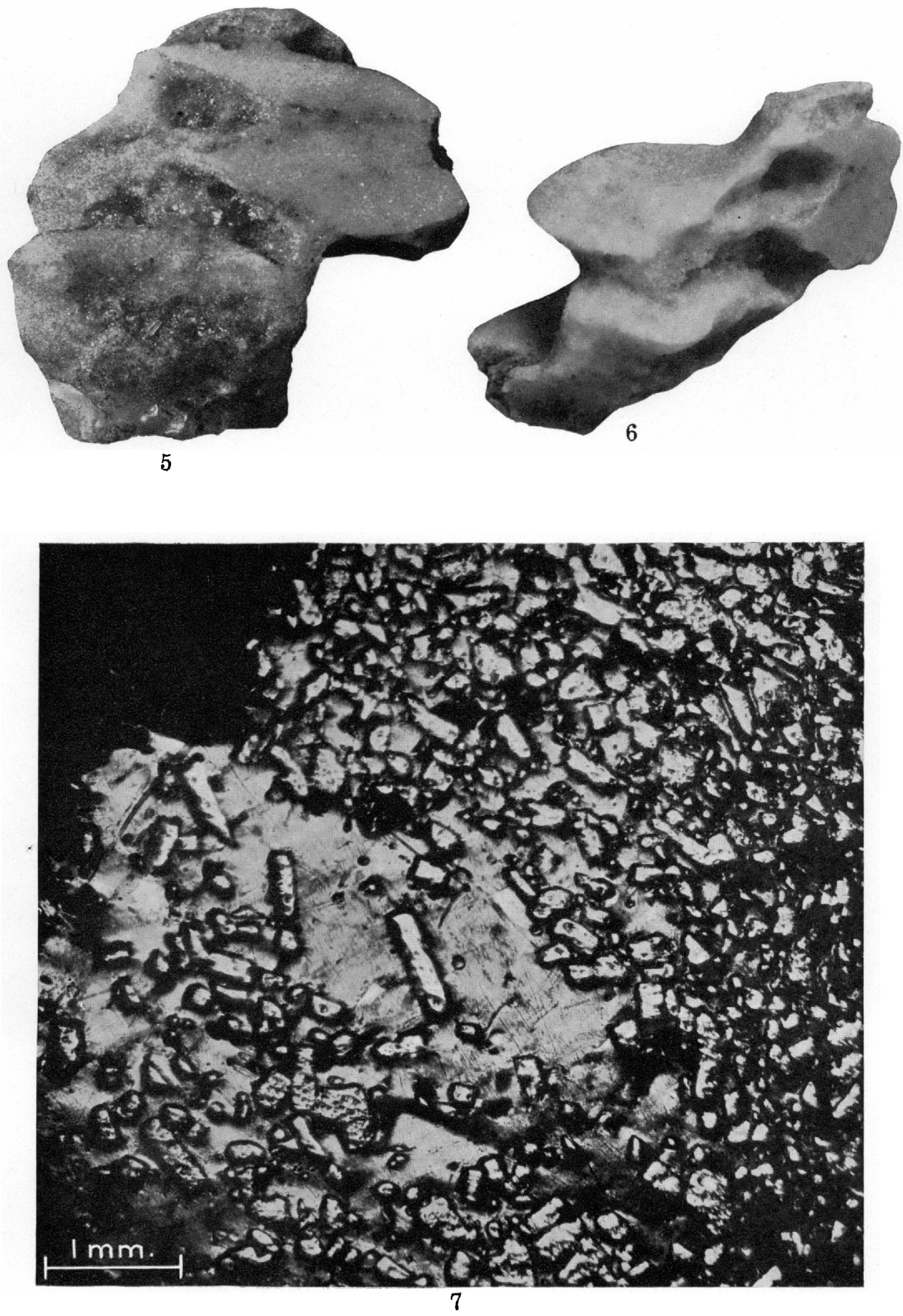
J. S. GEOLOGICAI SURVEY

PROFESSIONAL PAPER 175 PLATE 27

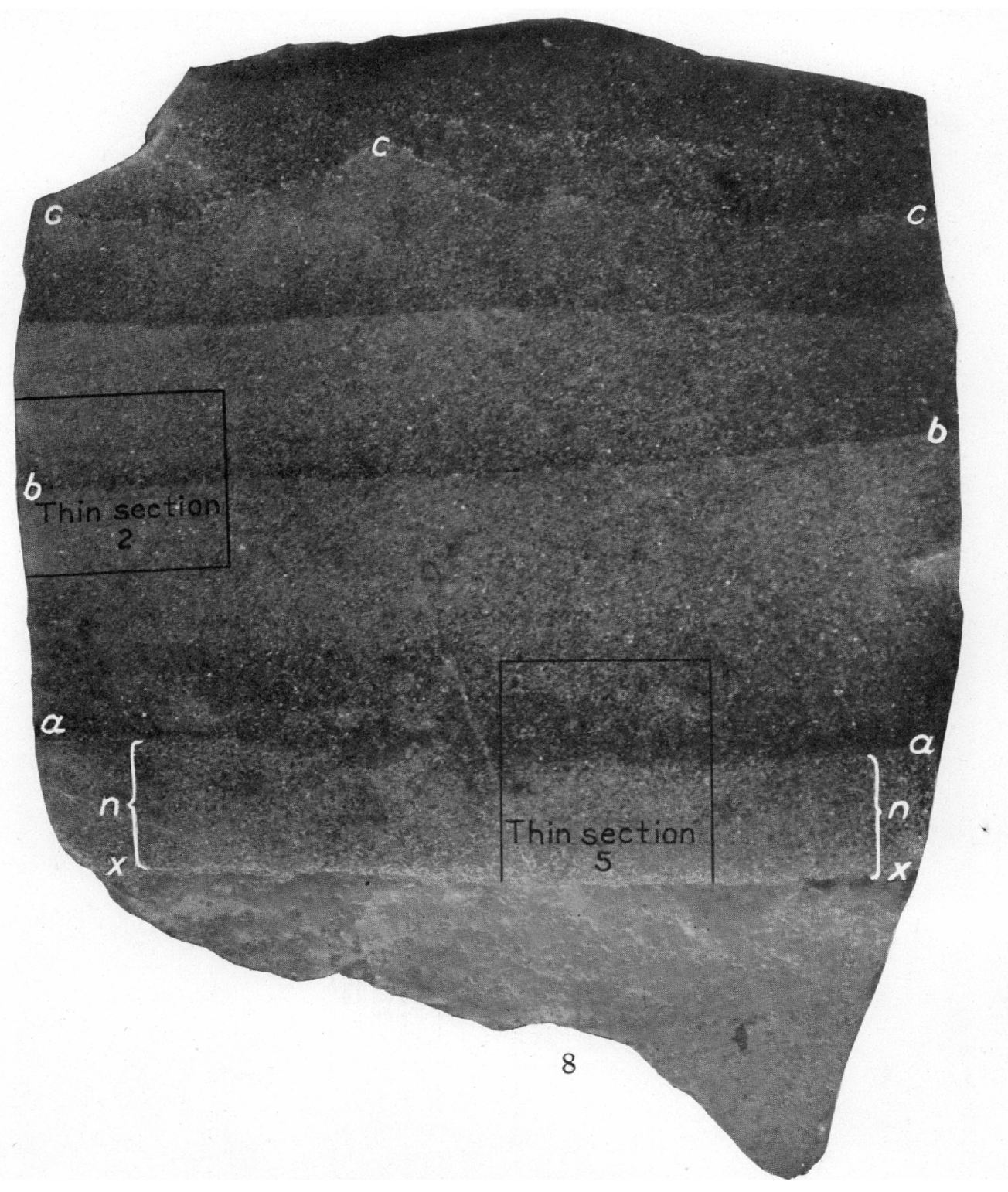




\section{PLA'TE 27}

Fig URE 8. Contact $(x-x)$ of banded anhydrite cap rock and salt; from the shaft of the Houston Salt Co. on the Hockley salt dome, Harris County, Tex. The band $n-n$ directly above the salt is an intergrowth of salt and anhydrite in varying proportions along different parts of the band. $a-a, b-b, c-c$ mark katatectic surfaces, intervening bands being katatectic bands. Note the irregularity of the boundary $c-c-c$. This boundary has been slightly emphasized in the illustration. U.S.N.M. 97791. Natural size. Specimen received from Mr. L. P. Teas, of the Humble Oil \& Refining Co., Houston, Tex. (See pp. 87, 89, 91, 92.) 


\section{PLATE 28}

FIGURE 9. General view of thin section 5 of the specimen of figure 8 , showing the contact of the lowest anhydrite band $n$ - $n$ with the one above it. Before grinding the thin section, the chip to be used was boiled in water to remove salt. The pores thus created were filled with bakelite, which appears dark in the illustration. The approximate position of the ends of the contact of the two bands is marked $a-a$, as in figure 8 . The boundary does not appear much more distinct under the microscope than in the illustration. (See pp. 84, 87, 91.)

Fig URE 10. General view of thin section 2 of the specimen of figure 8 , showing the contact $(b-b)$ of the two bands. The contact appears somewhat more distinct under the microscope than in the illustration. (See pp. 84, 87, 91.)

100 

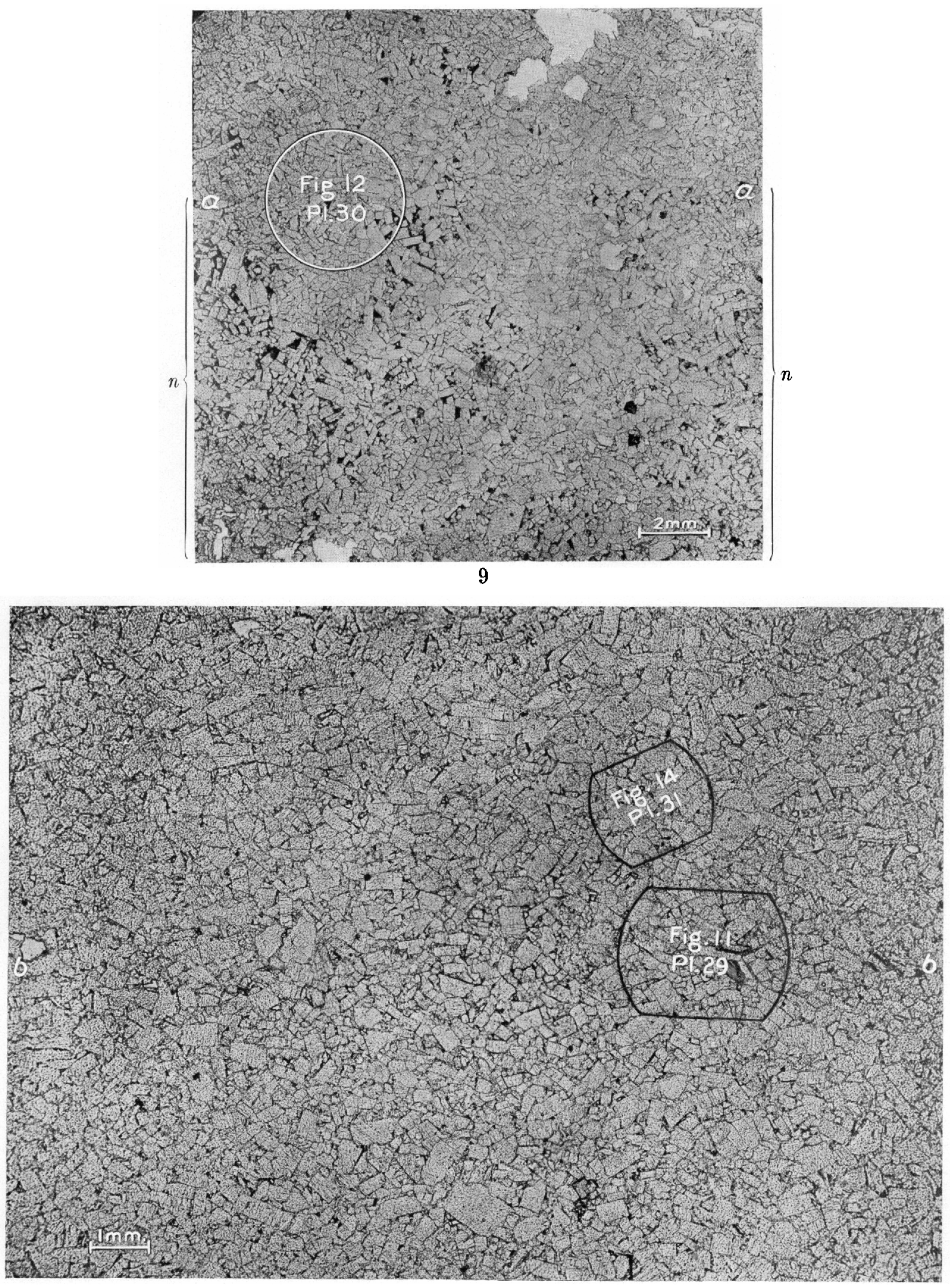
PROFESSIONAL PAPER 175 PLATE 29

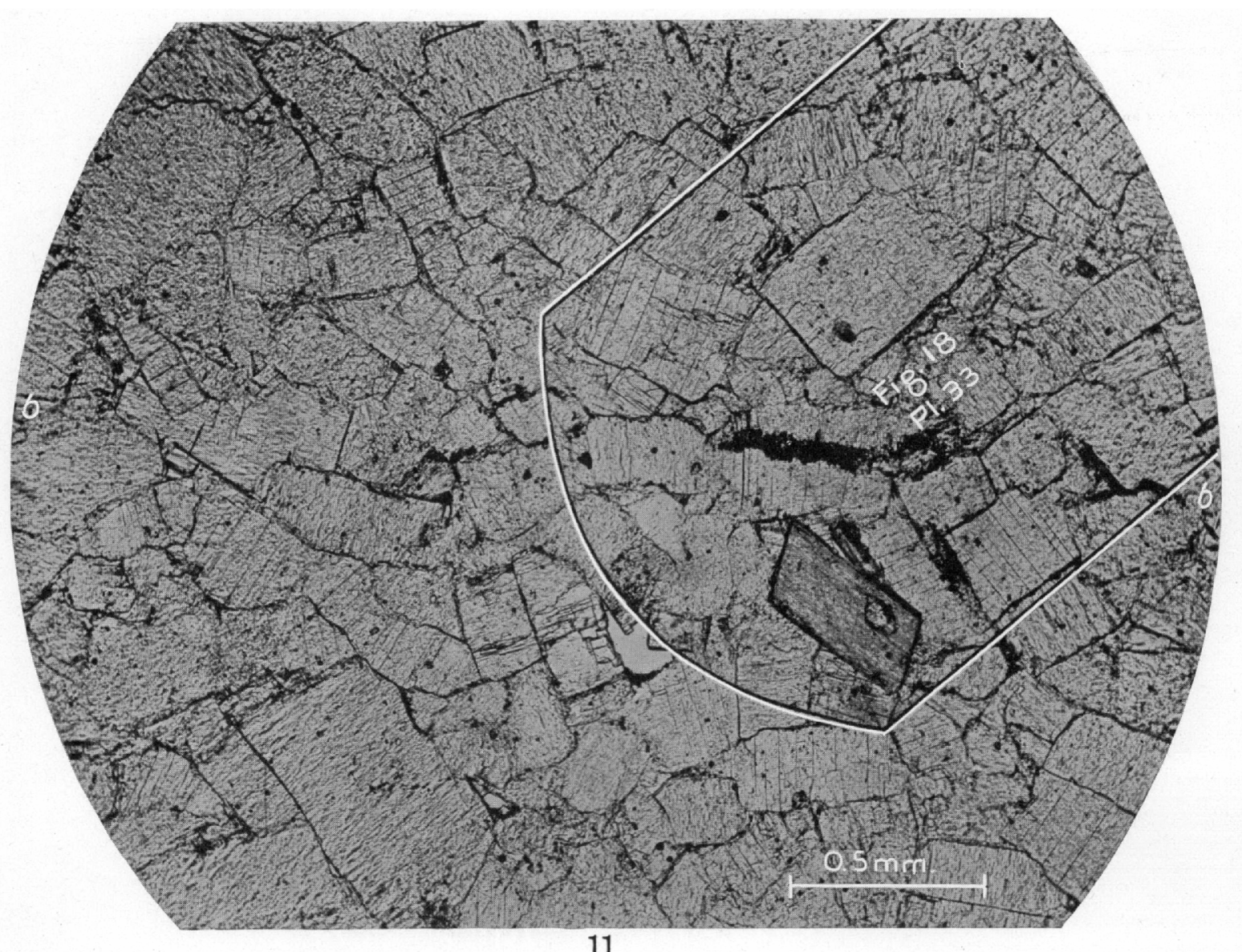




\section{PLATE 29}

FiguRE 11. Detail of thin section 2, figure 10, to show the irregular distribution of impurities along the contact of two bands. The stringers and patches of dark material distributed along an irregular line between the points $b-b$ are the impurities. Quartz crystals are numerous. The rest of the impurities are too fine for certain identification but appear to be fine-grained carbonate, sulphides in more or less spherular forms, and some sulphur. The position of the area illustrated in this figure is shown in the more general view of this thin section in figure 10 . (See pp. 84, 87, 91.) 
PLATE 30

Figures 12 and 13. Detail of thin section 5, figure 9, to show crushing and straining along the surface $a-a$ (12, plain light; 13 , crossed nicols). The crushing and straining of the crystal $o$ and of the crystals around it are clearly shown, and crushing and straining can also be plainly seen around $p$. The area of figure 12 is indicated in figure 9 . (See pp. 84, 87, 91.)

102 


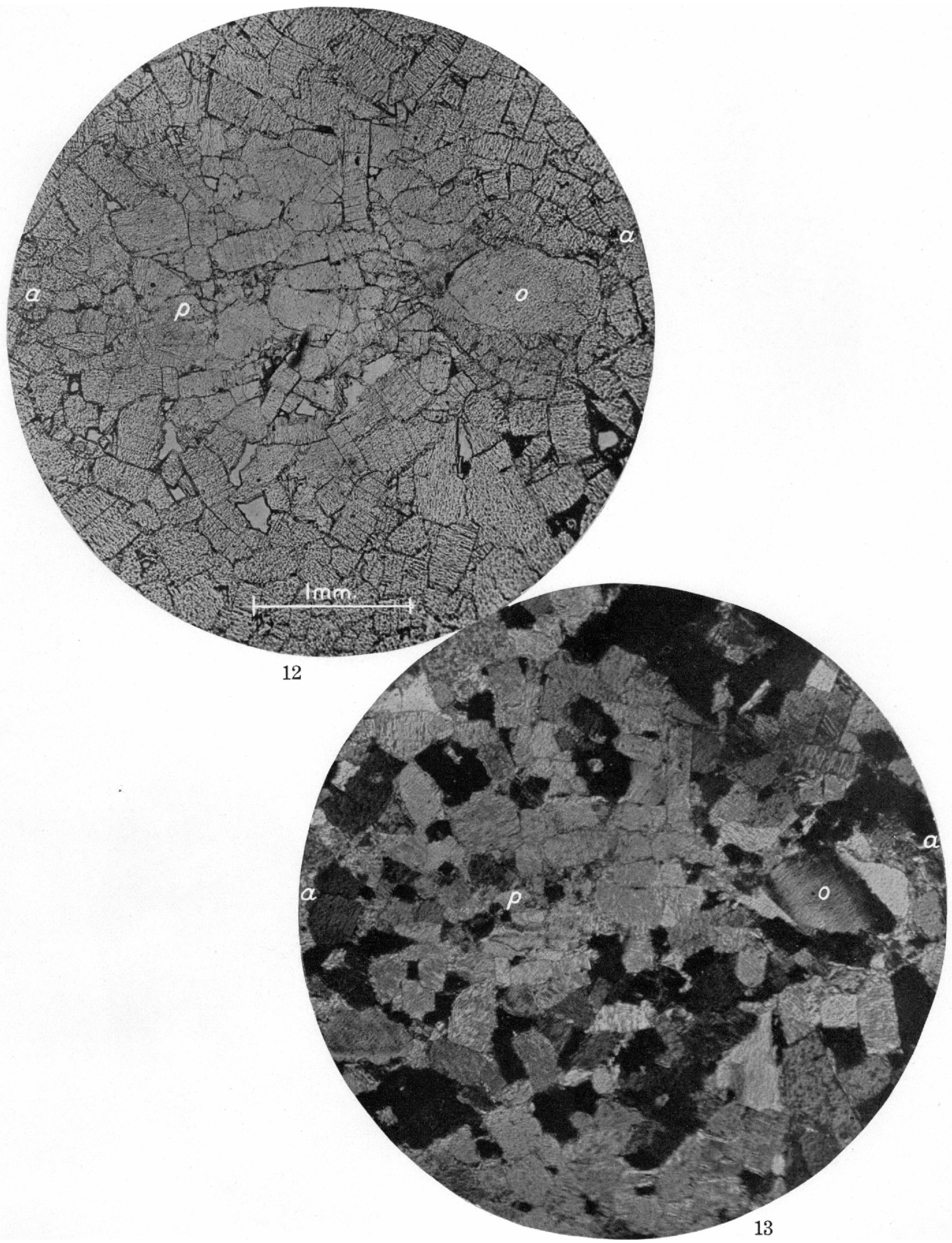




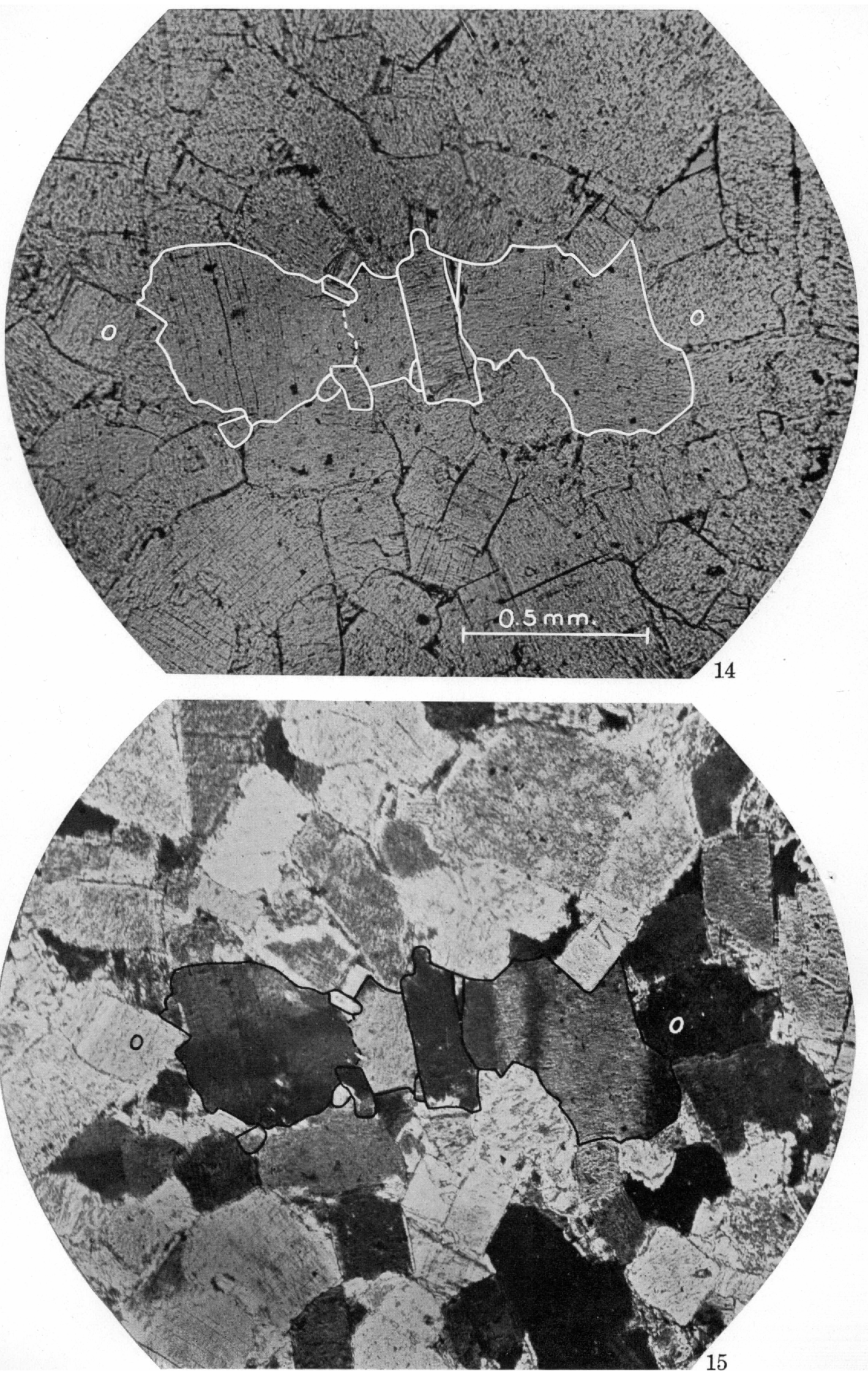




\section{PLATE 31}

FIGURES 14 and 15. Detail of thin section 2, figure 10, to show straining, but without appreciable crushing, within a katatectic band (14, plain light; 15 , crossed nicols). The straining, brought out between crossed nicols, is mainly in the row of crystals along $0-0$. The approximate boundaries of individual erystals in the strained group have been emphasized in the figures, in order to make the straining more readily recognizable. The position of the area of these figures is shown in figure 10. (See pp. 84, 87, 91.) 


\section{PLATE 32}

FIgURES 16 and 17. Detail of thin section 2, figure 8, showing a crushed patch not along the contact of two bands (16, plain light; 17, crossed nicols). Here the crushing, which is quite distinct between crossed nicols under the microscope, is difficult to recognize in the photographs. Strain can be seen in the large crystals around the edge of the area of the figure at $o$, $o$, and $o$. Under the microscope general crushing is most conspicuous in the area around $p$ and in the figures is indicated by the poor definition of many of the crystals. (See pp. 84, 87, 91.)

104 

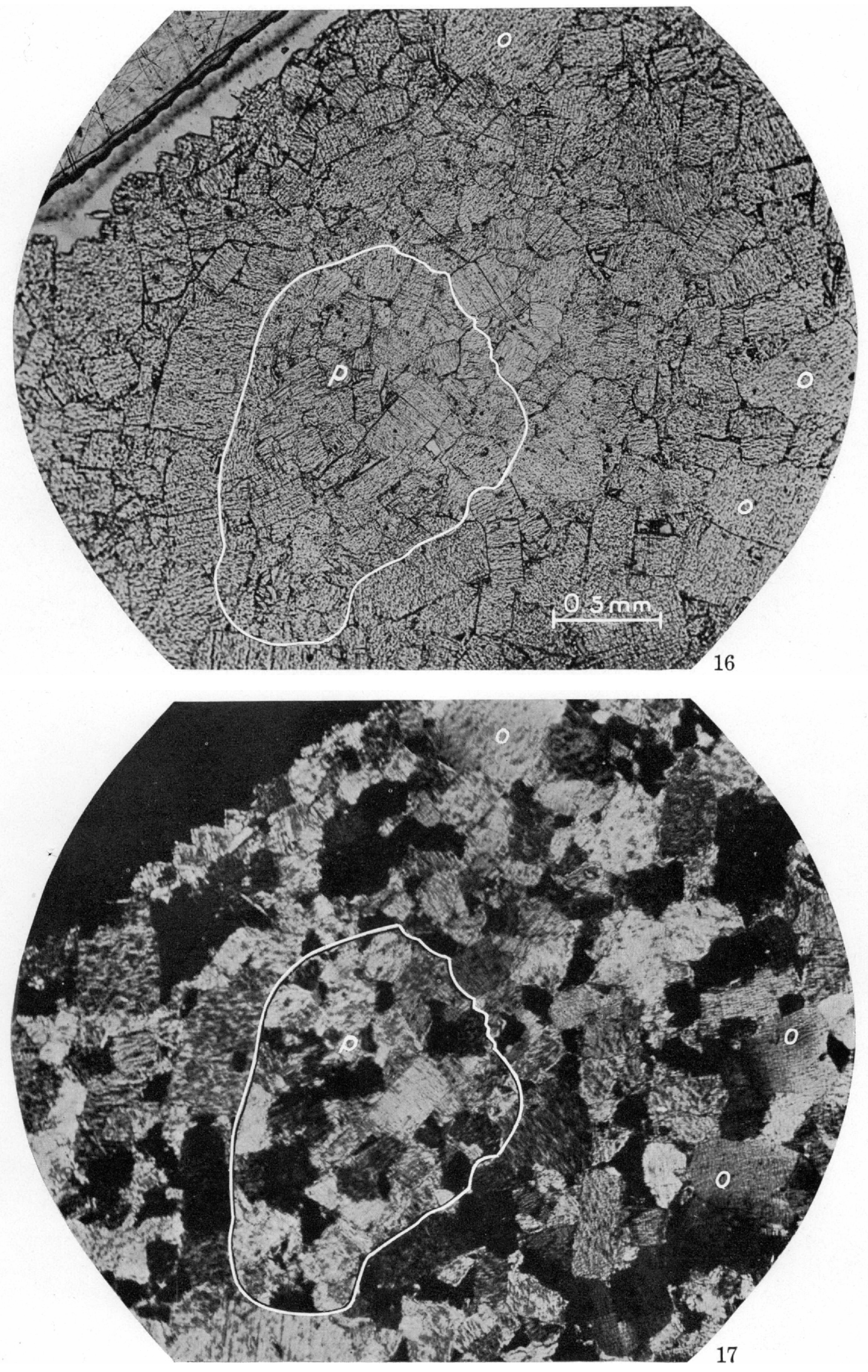

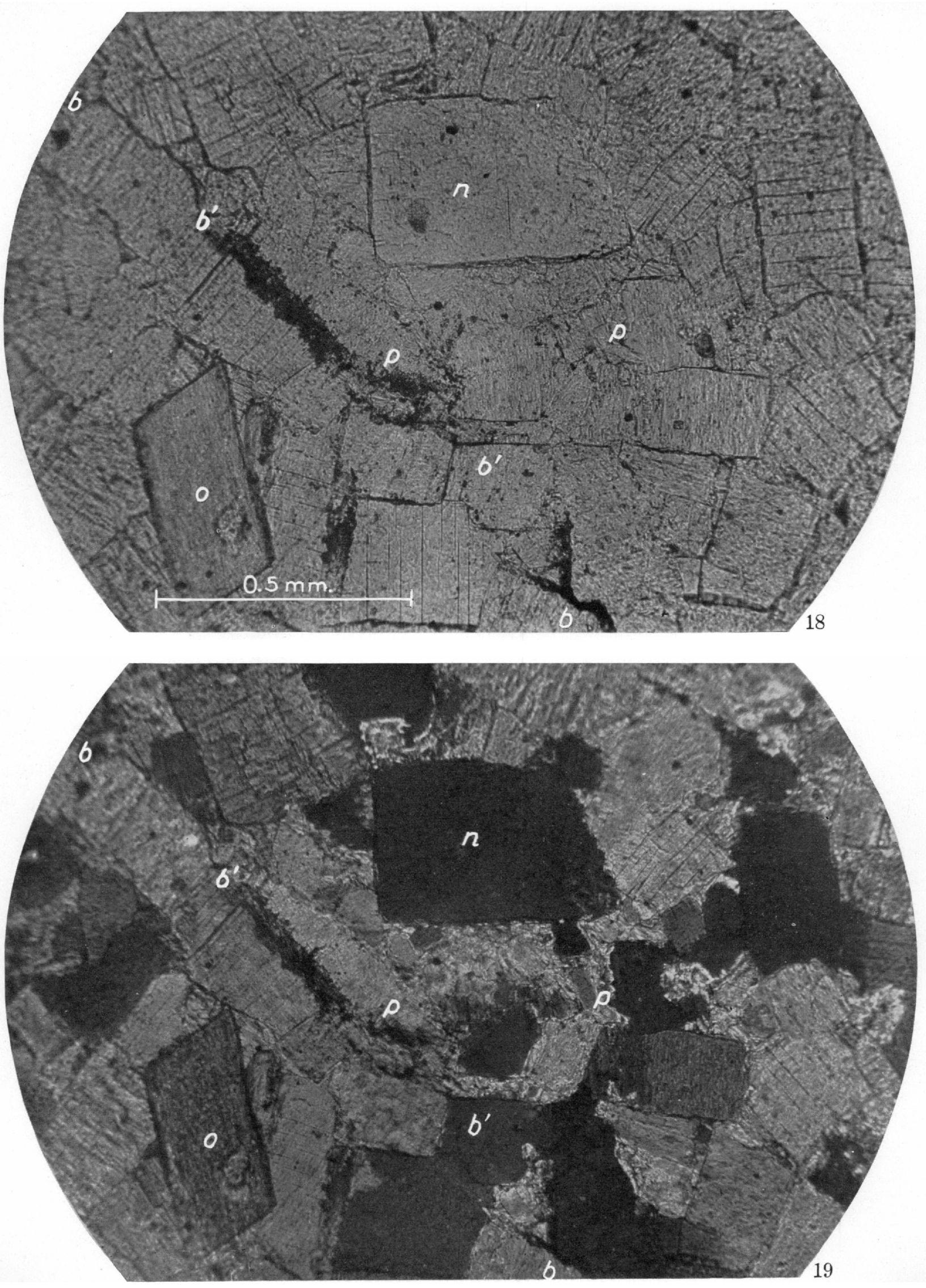


\section{PLATE 33}

Figures 18 and 19. Detail of figure 11, showing impurities and crushing along the contact of two bands (18, plain light; 19, crossed nicols). The dark material along an irregular line between the points $b$ and $b$ consists of the impurities. The crushing can be most readily recognized between crossed nicols in the general area between the heavy band of impurities, $b^{\prime}-b^{\prime}$, and the crystal $n$, especially just below the crystal $n$. Note especially the comblike arrangement of fragments between the points $p$ and $p$. $o$ is a crystal of a carbonate, probably dolomite. The area of this thin section is shown in figure 11, and the area of figure 11 is shown in figure 10 . (See pp. $84,87,91$.) 


\section{PLATE 34}

Figure 20. Polished face of specimen La. 1, 1014-1023, 107-1101/4,1 a solid primary sedimentary anhydrite rock showing no recognizable stratification seams. There are two slightly darker bands running across the specimen at $a-a$ and $b-b$, but these are even more distinct in the illustration than in the specimen. These seem too faint and indefinite to be stratification bands. The darker spots along the bottom between $c$ and $c$ represent gypsified portions. U.S.N.M. 97792. Natural size. (See p. 89.)

Frgure 21. Polished face of specimen La. 1, 1023-1033, 1031/4-106. A large fragment of primary sedimentary anhydrite with unusually clear and pronounced but widely separated stratification seams, $n-n, n^{\prime}-n^{\prime}, n^{\prime \prime}-n^{\prime \prime}$, showing distortion. The series of dark spots across the stratification along the line $a-a$ is due to gypsification. U.S.N.M. 97792. Natural size. (See pp. 87, 89.)

FIGURE 22. Polished face of specimen La. 1, 1286-1296, 76-783.4. A core consisting apparently almost entirely of primary sedimentary anhydrite rock but very much brecciated. Along the line $a-a$ a stratified fragment can be recognized, gradually passing into confused breccia. Dark distorted seams throughout the specimen, such as that at $b$, probably represent remnants of stratification banding similar to that in the fragment $a-a$. U.S.N.M. 97792. Natural size. (See pp. 87, 88.)

Figure 23. Polished face of specimen La. 1, 1248-1258, 393/4-45/4. Largest single piece of well-stratified primary sedimentary anhydrite rock encountered in this diamond-drill core; the stratification is unusually thin and pronounced but much distorted. Matrix anhydrite can be seen at the top and bottom of the specimen; that at the bottom has pronounced katatectic banding. The dark spots along the bands at the bottom are due to gypsification. U.S.N.M. 97792. Natural size. (See pp. 87, 89.)

1 All specimens marked La. 1, which corresponds to U.S.N.M. 97792, are parts of a diamond-drill core from well 194 of the Union Sulphur Co. on the Sulphur salt dome, Louisiana. The entire core was given to the Geological Survey by Mr. W. R. Keever, of that company. The first pair of numbers gives the depth to the top and bottom of the interval represented by the section of core in the box from which the specimen was taken. The second pair of numbers represents roughly the distance in inches from the top of the series of core fragments in the box to the top and bottom of the specimen. 
c. S. GEOLOGICAL SURVEY

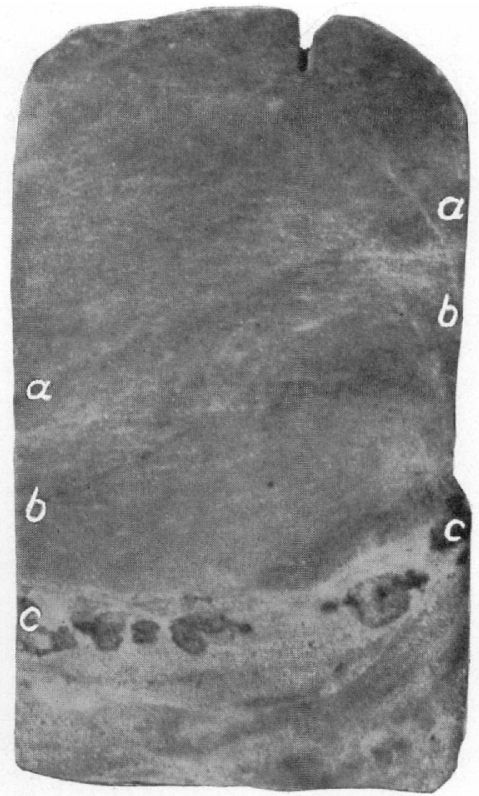

20
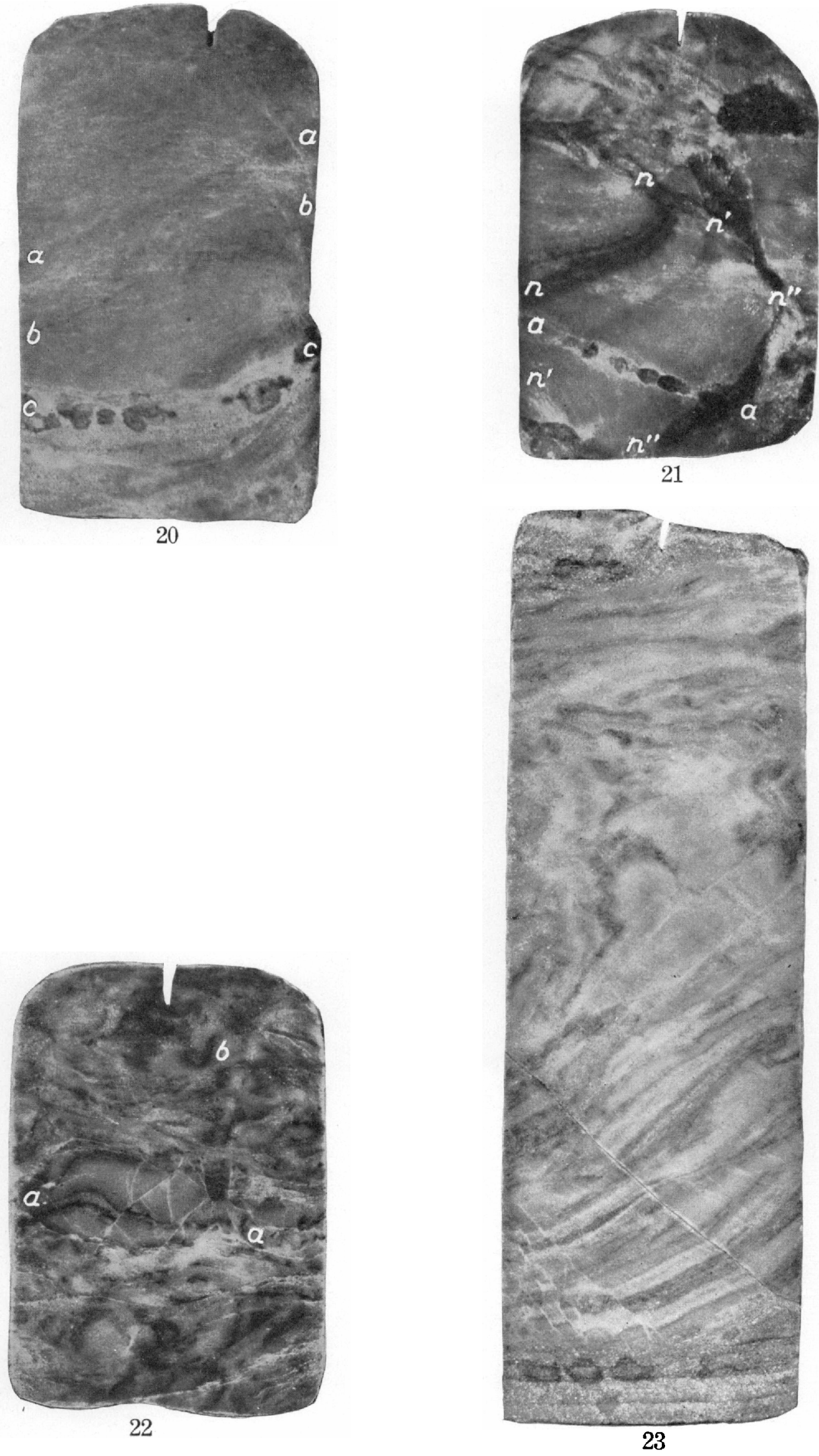
U. S. GEOLOGICAL SURVEY

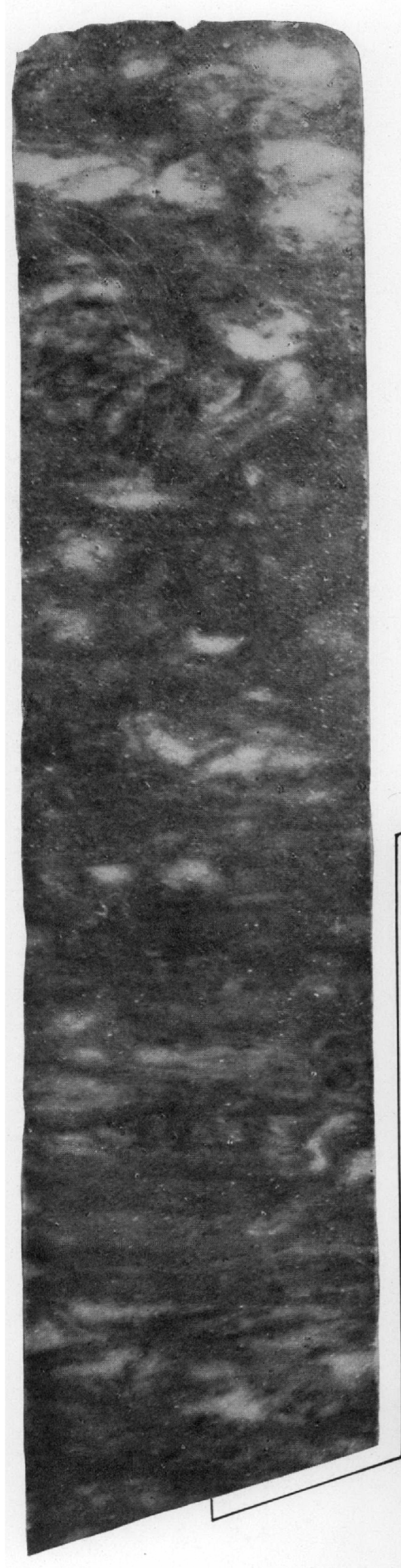

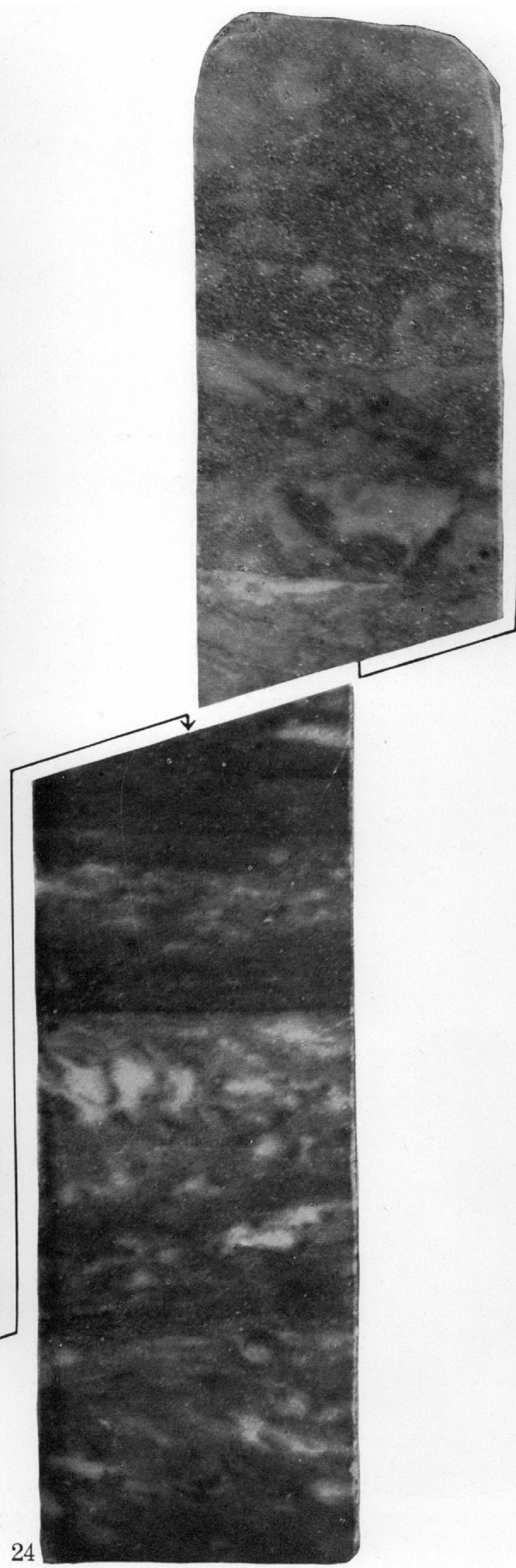

PROFESSIONAL PAPER 175 PLATE 35

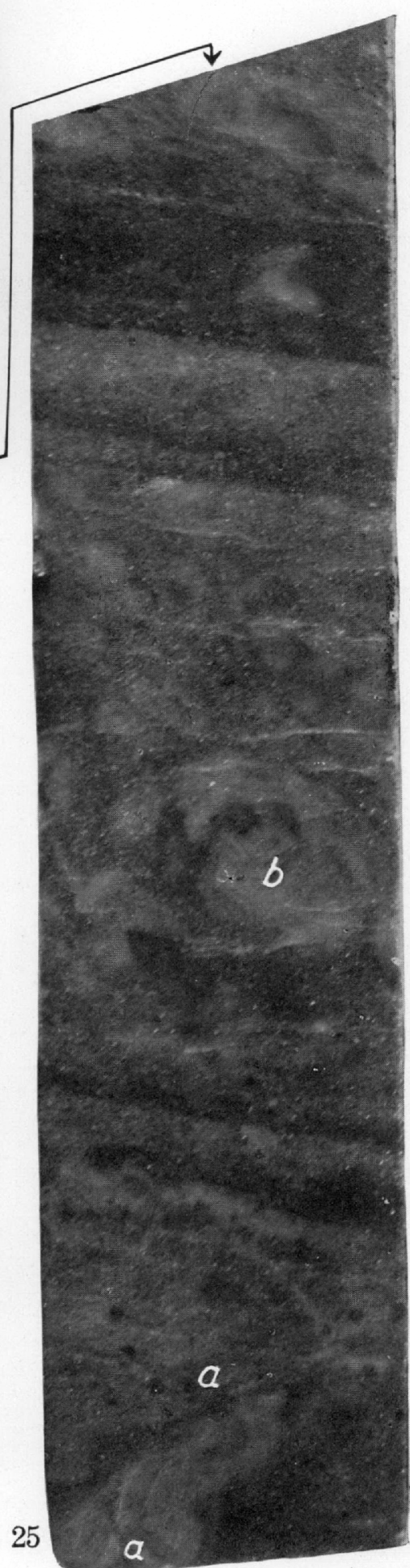




\section{PLATE 35}

Figure 24. Polished face of specimen La. 1, 1450-1458, 351/4-48\%1. An unusually long core showing primary katatectic anhydrite cap rock, with unusually long intervals showing little or no katatectic banding, adjacent to well-defined katatectic bands. U.S.N.M. 97792. About natural size. (See pp. 88-91.)

FIGURE 25. Polished face of specimen La. 1, 1228-1238, 631/2-75, show'ng considerable thicknesses of primary katatectic anhydrite cap rock, with little or no recognizable banding, in association with pronounced katatectic bands. Many breccia fragments, as at $a-a$ and $b$, show pronounced distortion. U.S.N.M. 97792. About natural size. (See pp. 87-91.) 


\section{PLATE 36}

Figures 26 and 27. Two polished faces of specimen La. 46, from depth of 2,354 feet, at the contact of anhydrite cap rock and salt, in the Texas Co.'s State Bay St. Elaine No. 3 on the Bay St. Elaine salt dome, Terrebonne Parish, La. The surface illustrated in figure 27 is about a quarter of an inch above that illustrated in figure 26. The specimen shows unusually clearly and thinly stratified, unusually well defined breccia fragments of primary sedimentary anhydrite, some of them distorted. In the breccia fragment $a$ there is a striking duplication of strata up and down, respectively, from the middle zone $n$ - $n$, which in figure 26 is dark. The duplication suggests that a long breccia fragment may have been broken about the middle and doubled over on itself on a hinge line whose intersection with the plane of the polished face would be at the point marked $c$. The way the area of convexity at the right-hand end of the fragment below this point seems to fit into the concavity at the right-hand end above it supports this suggestion. In figure 27 the assumed surface of contact, $n-n$, of the two halves is scarcely recognizable, and in thin section 1, illustrated in figure 33, which was made from the area indicated in figure 27 , it is consequently also not pronounced. Somewhat coarser anhydrite can, however, be recognized along this line $n-n$ in figure 33 . If this is a surface of contact between two fragments, the lack of separating material shown in figures 27 and 33 may be due to squeezing out of matrix anhydrite. The development of the zone $n-n$ in figure 26 may, however, be due merely to recrystallization, along a more pervious stratification boundary, and the apparent duplication above and below it may be merely accidental. Distinct schistosity can be seen in both the anhydrite and the underlying salt-in flgure 26 clearly recognizable in the anhydrite and somewhat recognizable in the salt. At the bottom of the anhydrite as seen in figure 26 there is an intergrowth with salt similar to that in the specimen illustrated in figure 8 , from the contact of anhydrite and salt on the Hockley salt dome. The specimen is said to be from the flank of the salt stock, and the slope of the contact and the schistosity of the specimen may be due to that fact. Specimen received from Mr. R. C. Stewart, of the Texas Co., Shreveport, La. U.S.N.M. 97793. About natural size. (See pp. 87-88.) 

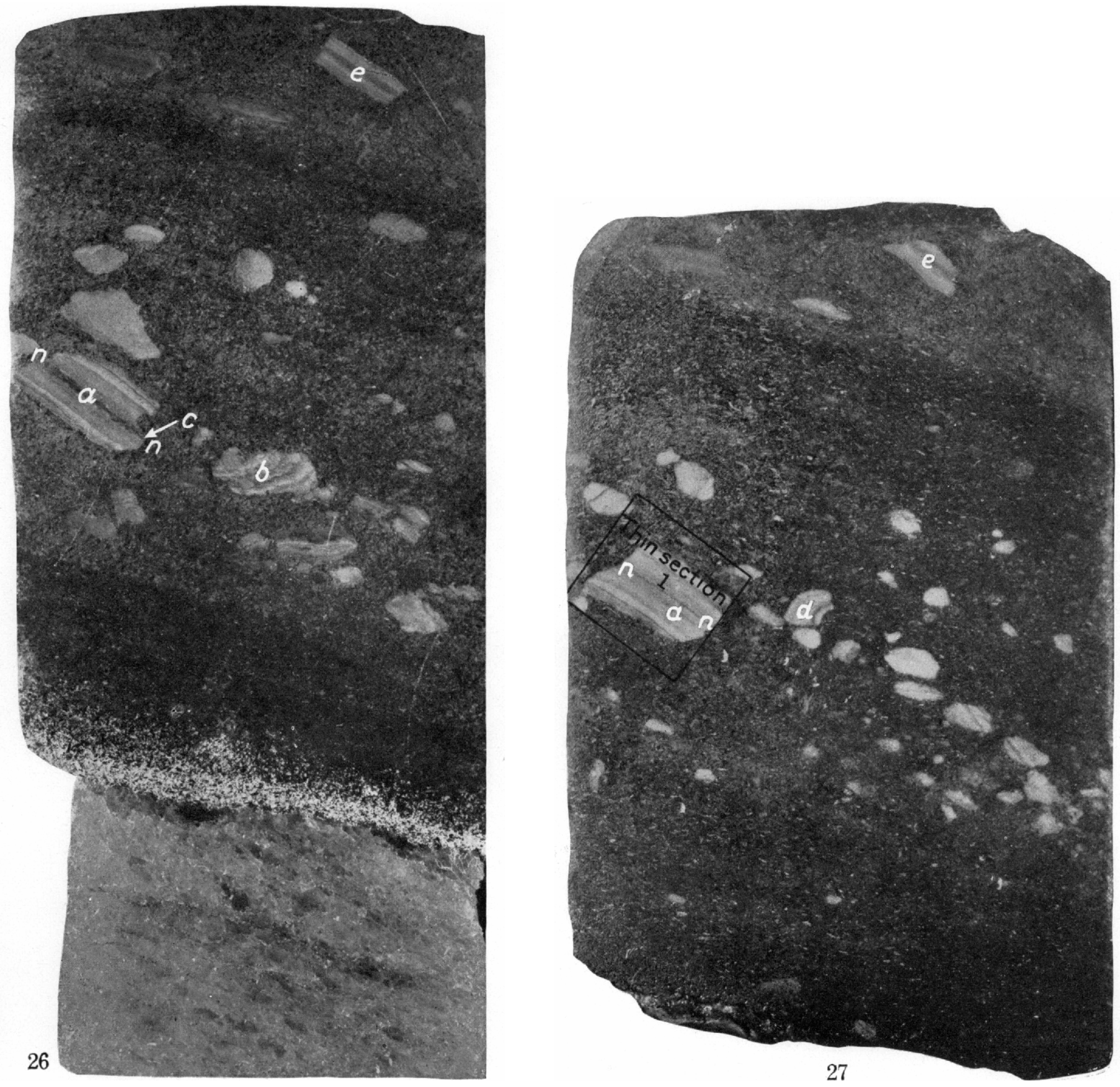

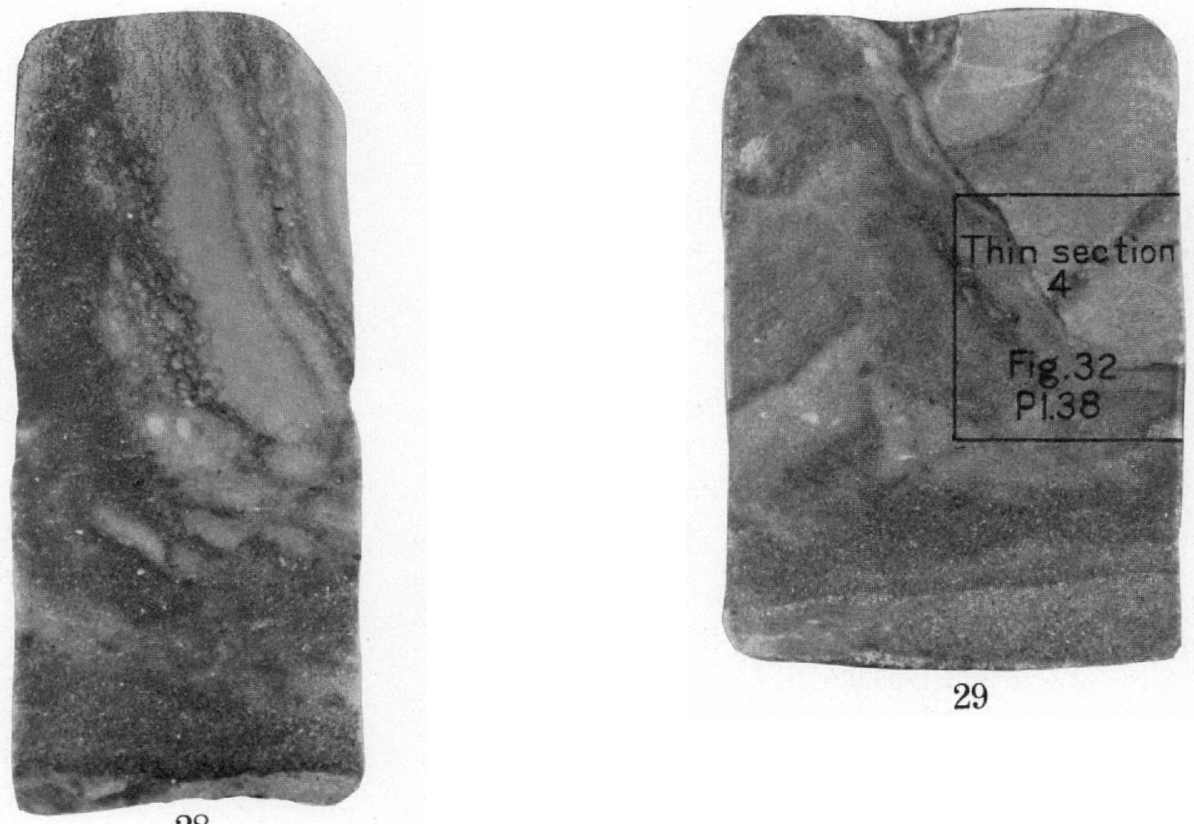

29

28

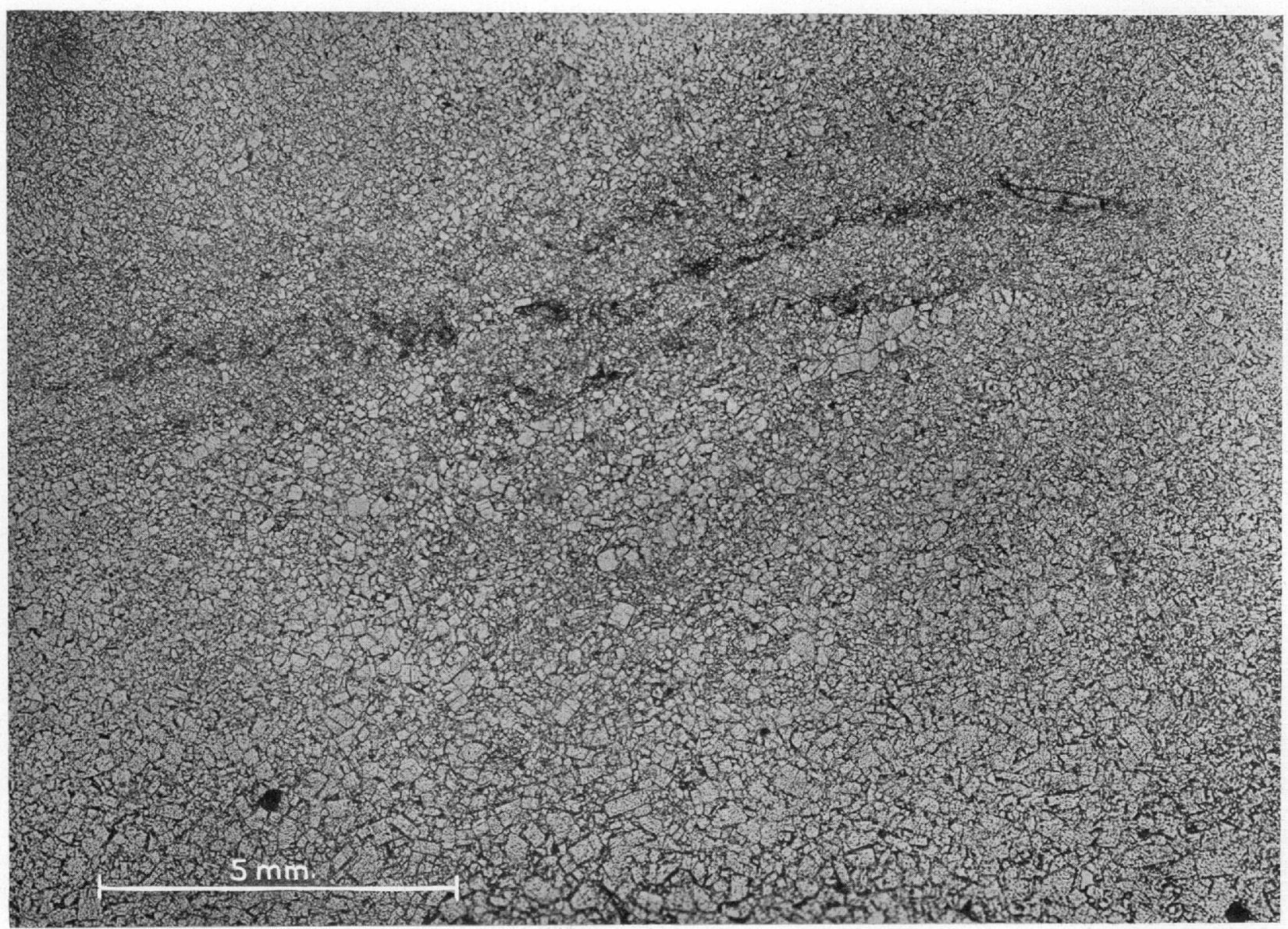




\section{PLATE 37}

Figure 28. Polished face of specimen La. 1, 1193-1203, 503/4-54. The specimen from this diamond-drill core that shows the best example of a breccia fragment of stratified sedimentary anhydrite rock; somewhat distorted. U.S.N.M. 97792. Natural size. (See p. 88.)

Figure 29. Polished face of specimen La. 1, 1238-1248, 993/4-1021/2. Another example, from this core, of a breccia fragment showing distinct stratification but with the stratification surfaces more widely spaced than in figure 28. U.S.N.M. 97792. Natural size. (See p. 88.)

FIGURE 30. Photomicrograph of a thin section of the specimen illustrated in figure 28, showing the appearance of the impurities along the stratification surfaces and something of the relation of the breccia fragment to its matrix. The fine-grained portion in the upper part is the breccia fragment. The coarser-grained material in the lower part is the matrix. On account of recrystallization, as can be seen in figure 28 , the boundary is here not sharp. (See pp. 84,88 .) 


\section{PLATE 38}

FIGURE 31. Detail of figure 32, to show more clearly the relative size and shape of grain and the sharpness of the contact of the clast and the matrix. (See pp. 84, 88.)

FIGURE 32. Photomicrograph of thin section 4 of the specimen shown in figure 29, illustrating the relation of the fine grain of the breccia fragment to the coarse grain of the matrix, the sharpness of the contact, and the very slight indications, in this section, of the stratification surface. This surface may perhaps be indicated by a very vague zone of parallel orientation of the anhydrite crystals recognizable on close study of the thin section. The approximate position of the thin section is indicated in figure 29 . (See pp. 84, 88.)

110 


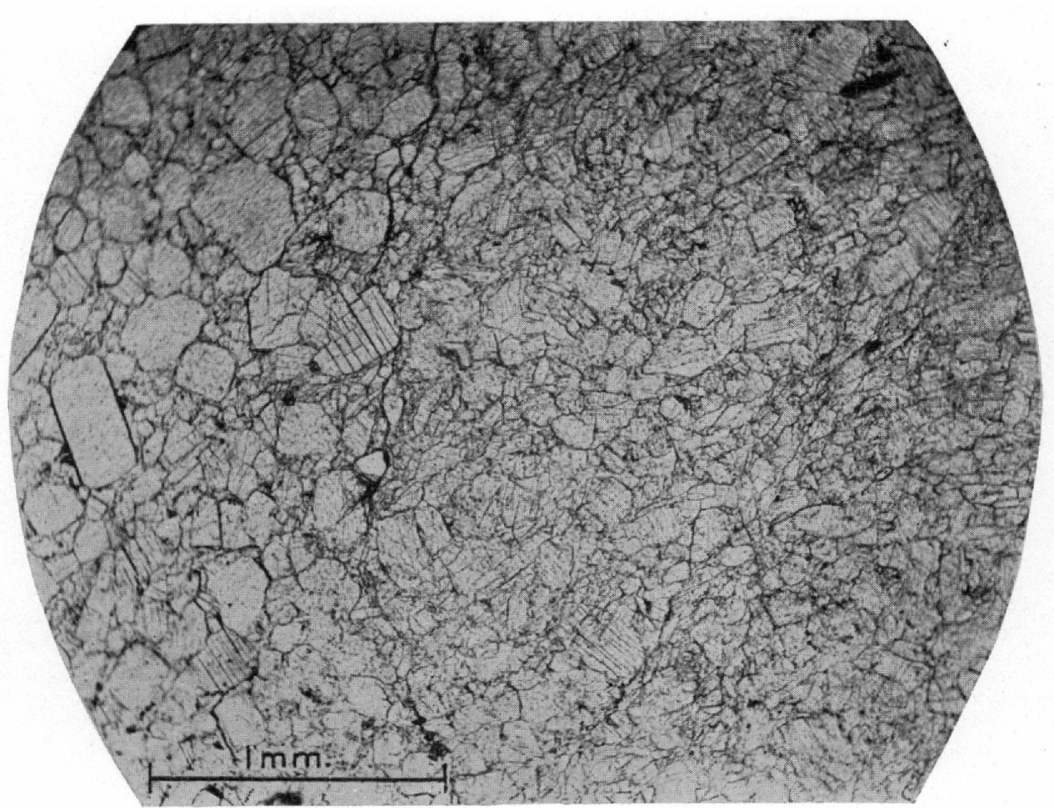

31

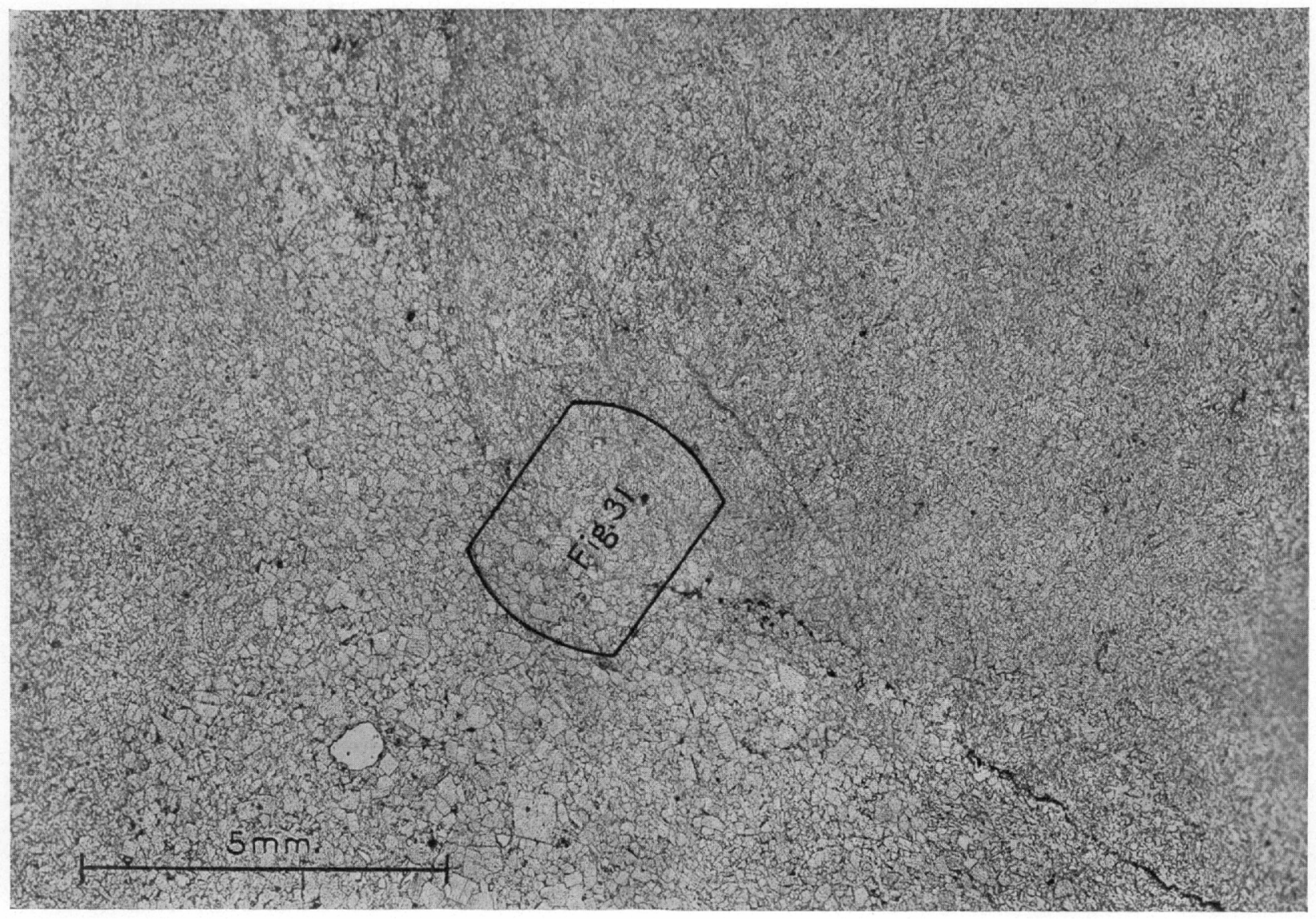



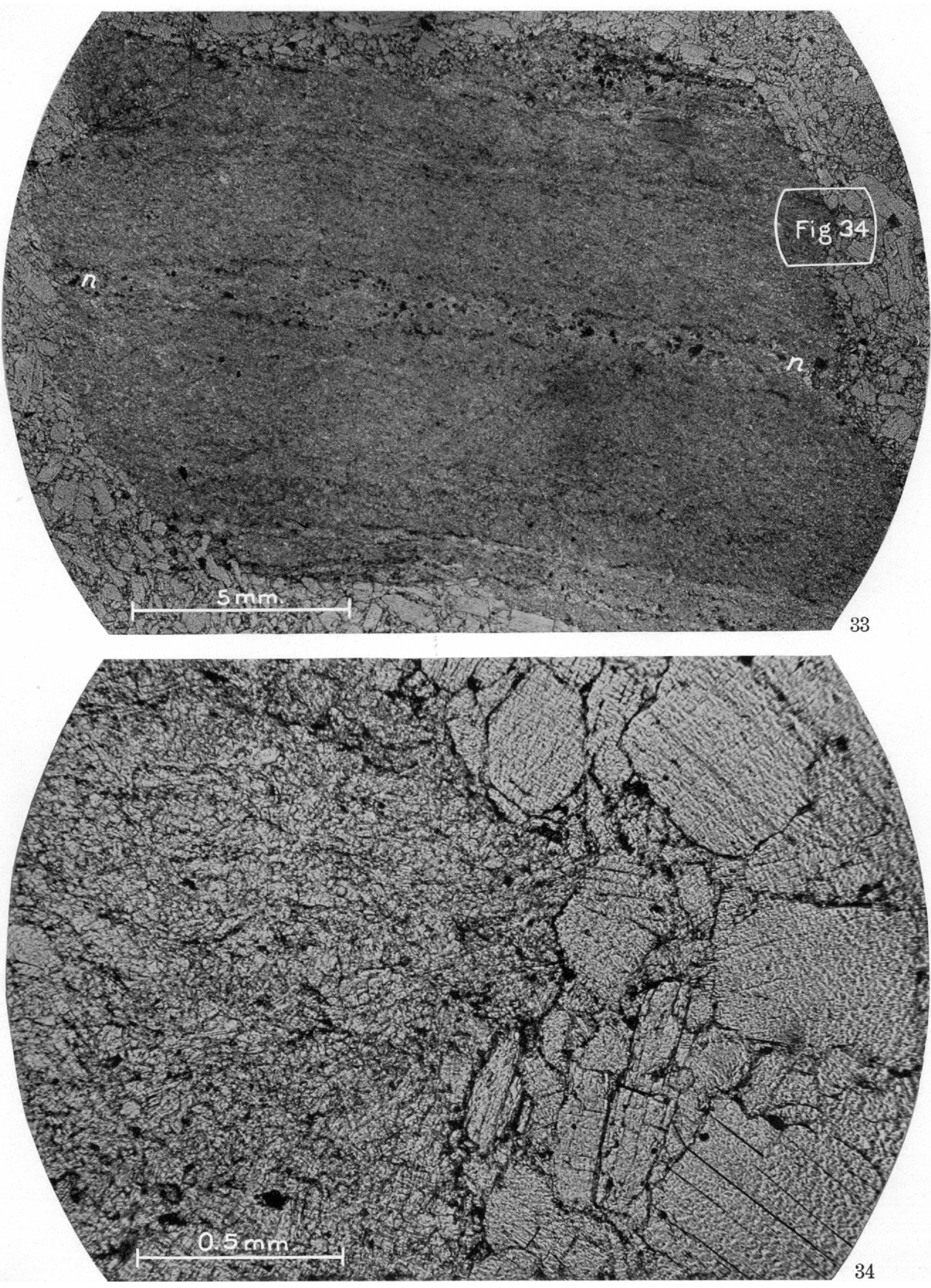


\section{PLATE 39}

FIGURE 33. Photomicrograph of thin section 1, figure 27, showing a particularly clearly stratified breccia fragment of primary sedimentary anhydrite rock and its matrix. It is worth noting that the stratification does not appear as pronounced as would be expected from the polished face illustrated in figures 26 and 27 . In view of this, it is not so surprising that stratification, such as that illustrated in figure 29 , should be scarcely recognizable in the thin section of the same material illustrated in figure 32 , and that it should be poorly defined in figure 30 . The possible significance of the line $n$ - $n$, along which some coarser anhydrite can be seen, as a line of contact between two fragments of the same breccia fragment, is more fully discussed in connection with figures 26 and 27 . (See pp. 84, 88.)

FIGURE 34. A detail of the area indicated in figure 33, showing the sharp contact between breccia fragment and matrix and the relative size of grain of the two. This enlargement of the breccia fragment shows, in greater detail, the internal structure of such a fragment of what is taken to be primary sedimentary anhydrite. As may be seen, the grains are generally small but differ widely in size, are very irregular in outline, and show no regular orientation in spite of the pronounced banding of the breccia fragment as a whole. (See pp. 84, 88.) 


\section{PLATE 40}

FlGURE 35. Polished race of speeimen La. 1, 1339-1348, 86 ${ }^{3}{ }_{4}^{\prime}-89 \frac{1}{2}$. An example of ordinary katatectic anhydrite cap rock showing stratified breccia fragments and matrix, but the breccia fragments less sharply defined than in the specimens illustrated in figures 26, 27, 28, and 29. U.S.N.M. 97792. Natural size. (See pp. 88, 90.)

Figure 36. Polished face of specimen La. 1, 1434-1438, 371/2-483/4. Illustrates the same thing as figure 35 . The black lines around and in so many of the breccia fragments in this specimen are striking and unusual. Comparison with figure 22 suggests that these black lines are perhaps distorted stratification seams and that the stratified sedimentary anhydrite rock from which breccia fragments of this specimen were derived was particularly clearly and perhaps closely stratified. U.S.N.M. 97792. About natural size. (See pp. 88, 90, 91.)

Figure 37. Polished face of specimen La. 1, 1438-1442, 181/4-221/2. The specimen from this diamond-drill core most typically illustrating katatectic banding; the banding close and sharp and without recognizable breccia fragments in the bands. The white patch in the lower left part is due mainly to fine-grained carbonate. In the rest of the specimen the whiter parts are in general finer grained, probably because they are less recrystallized than the darker parts. U.S.N.M. 97792. About natural size. (See pp. 89, 91)

Figure 38. Polished face of specimen La. 1, 1348-1358, 78-81/1/4. Another specimen from this diamond-drill core showing pronounced katatectic banding, but the banding unusually converging and irregular. The convergence and irregularity are believed to be due to proximity to a fault. U.S.N.M. 97792. Natural size. (See p. 91.)

Figure 39. Polished face of specimen La. 1, 1442-1450, 421/2-451/4. Illustrates another one of the few examples of convergence of katatectic surfaces in this core. The specimen is very near a fault or some similar disturbance, to which the generally disturbed appearance and the convergence of the katatectic surfaces in the lower part are ascribed. U.S.N.M.. 97792. Natural size. (See p. 91.) 


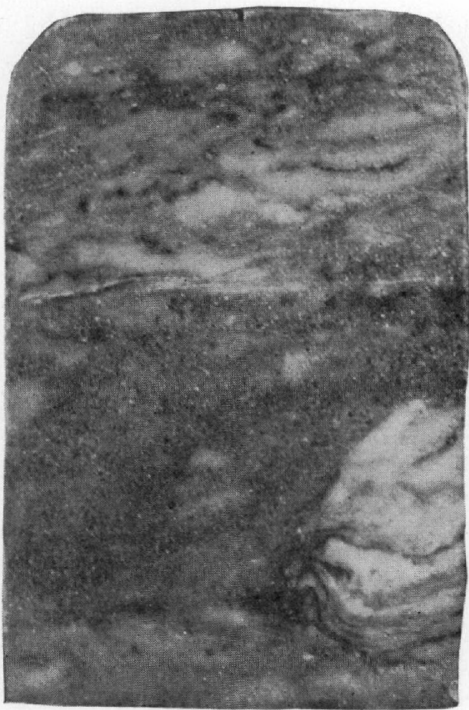

35

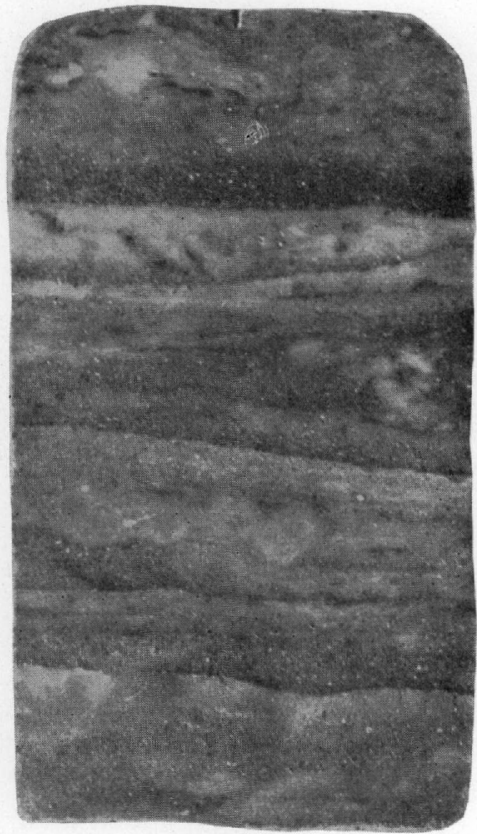

38

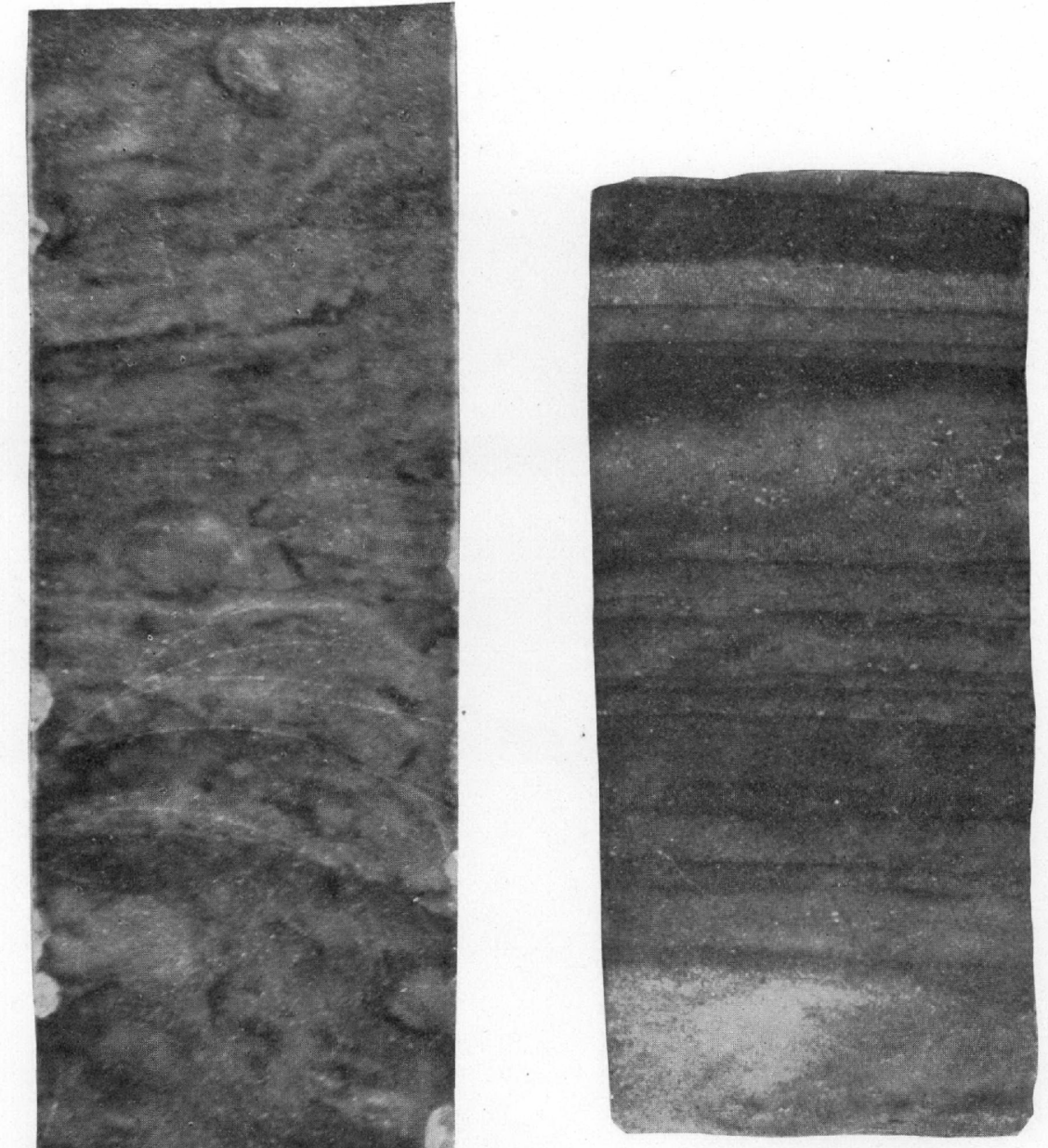

37

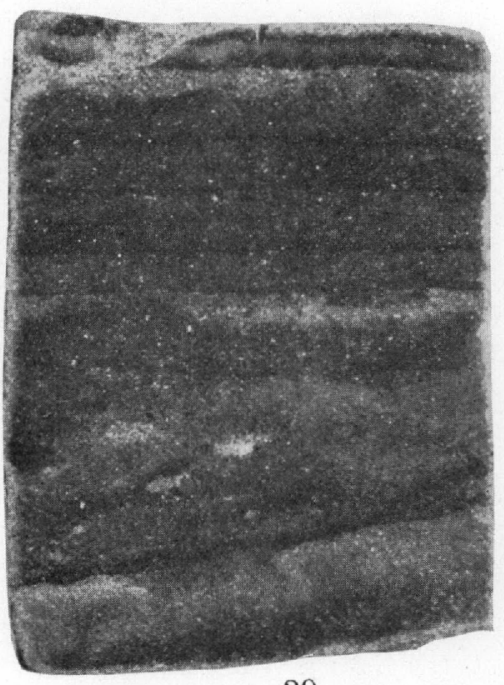

39 

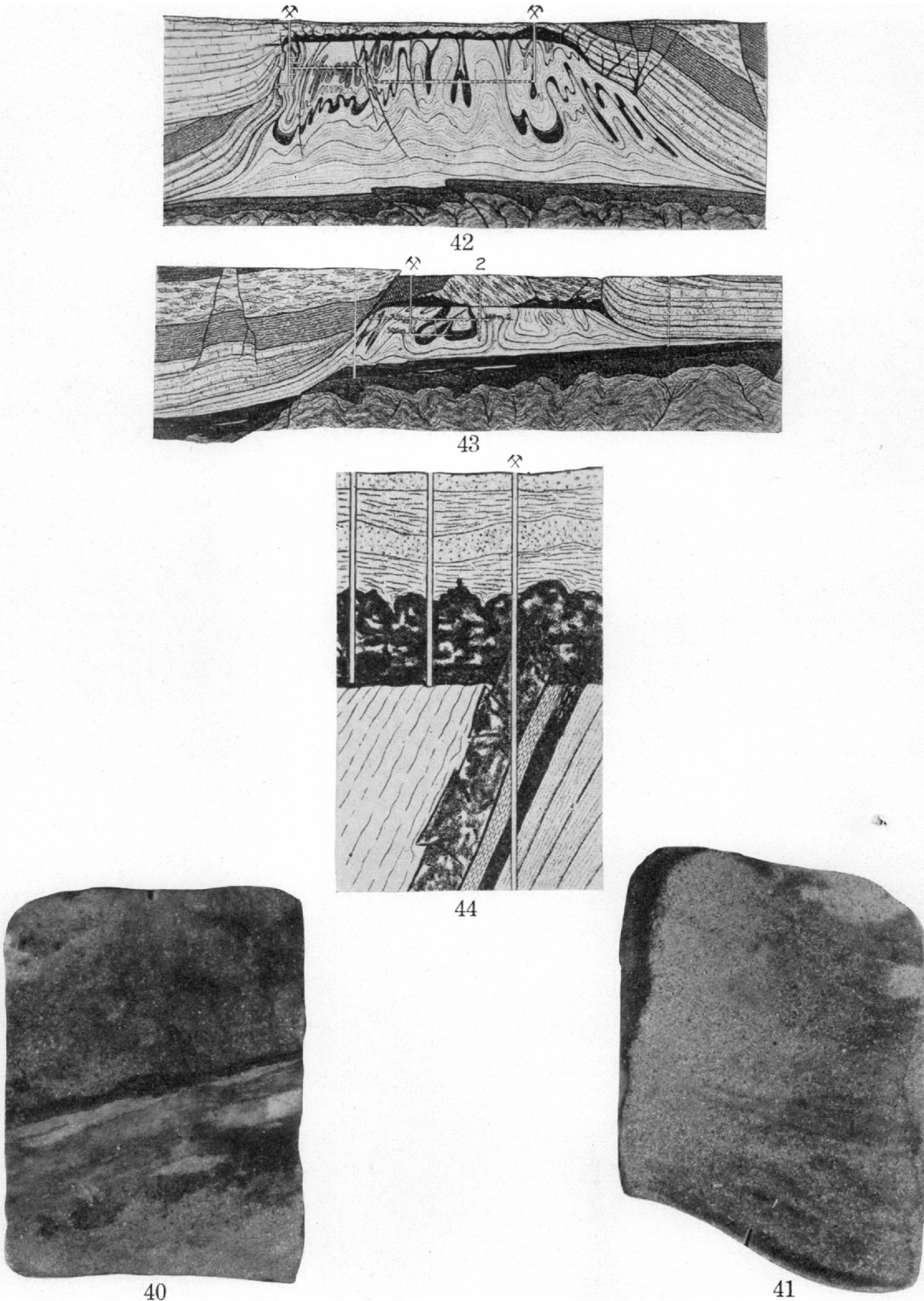


\section{PLATE 41}

FIGURE 40. Polished face of specimen La. 1, 958-968, 55/2-58. A rather unusual example of schistosity in the cap rock from this diamond-drill core. U.S.N.M. 97792. Natural size. (See p. 91.)

Figure 41. Polished face of specimen La. 1, 1450-1458, 681/2-70. An example of curving schistosity parallel to a curving surface of parting unusual in the cap rock from this diamond-drill core. The specimen came from the vicinity of a fault. U.S.N.M. 97792. Natural size. (See p. 91.)

FigURE 42. Diagram from Seidl,2 showing complex folds, including an anhydrite bed in a German salt stock, and the truncation of these folds by the salt table, which is overlain by gypsum-anhydrite cap rock. The conspicuous, not quite solidly black bed in the stock is anhydrite, and the similar material across the top of the stock is the gypsum-anhydrite cap rock. Immediately or almost immediately below the anhydrite bed is a bed of potash salt indicated by solid black, hard to differentiate in the illustration as here reproduced. Scale about 1:57,580. (See pp. 84-86, 90,93.)

Figure 43. Another example to illustrate the same thing as figure $42^{3}$ but showing a more complex relation between gypsumanhydrite cap rock and the anhydrite of the salt stock. Anhydrite and cap rock are indicated in not quite solid black, as in figure 42. Note that the absence of cap rock in drill hole 2 and the greater thickness in the shaft to the left of it are definitely established by these exploitations. The absence of cap rock in drill hole 2 seems at first surprising, because a pronounced anticlinal fold in the salt, which should have carried a large portion of the anhydrite bed well above the present salt table, has been decapitated by the salt table. The phenomenon is probably accounted for by the squeeezing out of anhydrite on anticlines and its accumulation in synclines, as explained in Seidl's paper on the Graf Moltke shaft (see footnote 9, p. 85) and illustrated in the small folds in the beds of anhydrite and of potash salt in figure 42 . (See pp. 84-86, 90, 93.) Scale about $1: 59,100$.

FigURE 44. Another diagram from the same source as figures 42 and $43,{ }^{4}$ showing a bed of anhydrite projecting above the salt table into the overlying gypsum-anhydrite cap rock. As this occurrence is penetrated by a shaft, it has apparently been definitely observed, and it shows clearly the intimate relation between anhydrite in the salt stock and the gypsum-anhydrite cap. According to the illustration, there is a transition from the anhydrite bed to the cap rock. The indicated thickness of this bed, some 35 meters, as well as the relatively slight overburden (the distance from the surface to the salt table is about 165 meters, or 560 feet) probably accounts for the distance, some 35 meters, that the bed projects into the cap rock. According to the interpretation presented in this paper, the cap rock between the level of the upper end of this bed and the salt table would constitute a $\sin _{5}-$ katatectic layer. The thickness of such a layer would be several hundred times the prevailing thickness of the katatectic layers I have seen in the anhydrite cap rock of American salt domes. The difference conforms to the evidence, discussed on pp. 84-85, that thick beds of anhydrite are not common in American salt stocks. Scale about 1:5,310. (See pp. $85,86,90$.

2 Seidl, Erich, Schürfen, Belegen und Schachtabteufen an deutschen Zechstein-Salzhorsten: Archiv für Lagerstätenforschung, Heft 26, fig. 45, p. 129, Preuss. geol. Landesanstalt, 1921.

Idem, fig. 46, p. 131 .

Idem, fig. 58, p. 165 


\section{PLATE 42}

Figdres 45 and 46. Core from a depth of about 950 feet in the Texas Exploration Co.'s Warren No. 1 well on the Hockley salt dome, Harris County, Tex., showing a breccia of calcareous rock fragments in sandy clay (45, outside surface; 46, polished face). This breccia might be made up of sedimentary beds that overlay, in depth, the bedded salt from which the salt of the salt stock is derived and that were brecciated when the salt broke through them to form the stock. U.S.N.M. 97794. About natural size. Specimen probably received from Mr. Statti, of the Texas Exploration Co., Houston, Tex. (See p. 93.)

114 


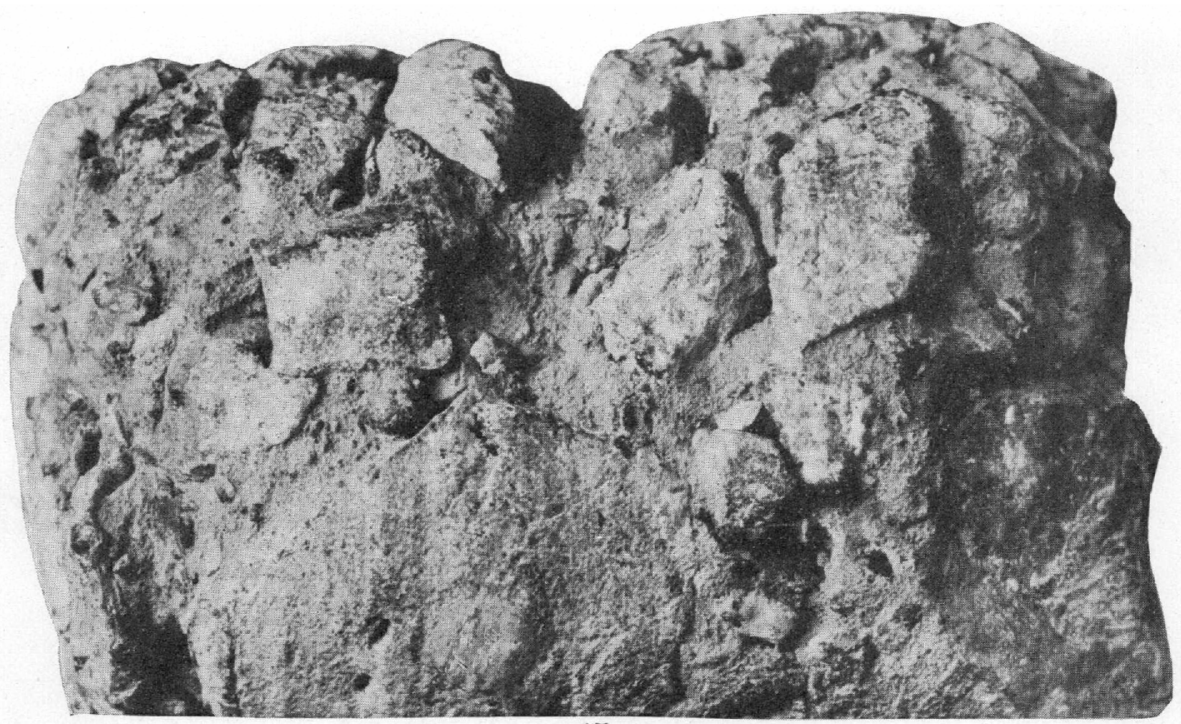

45

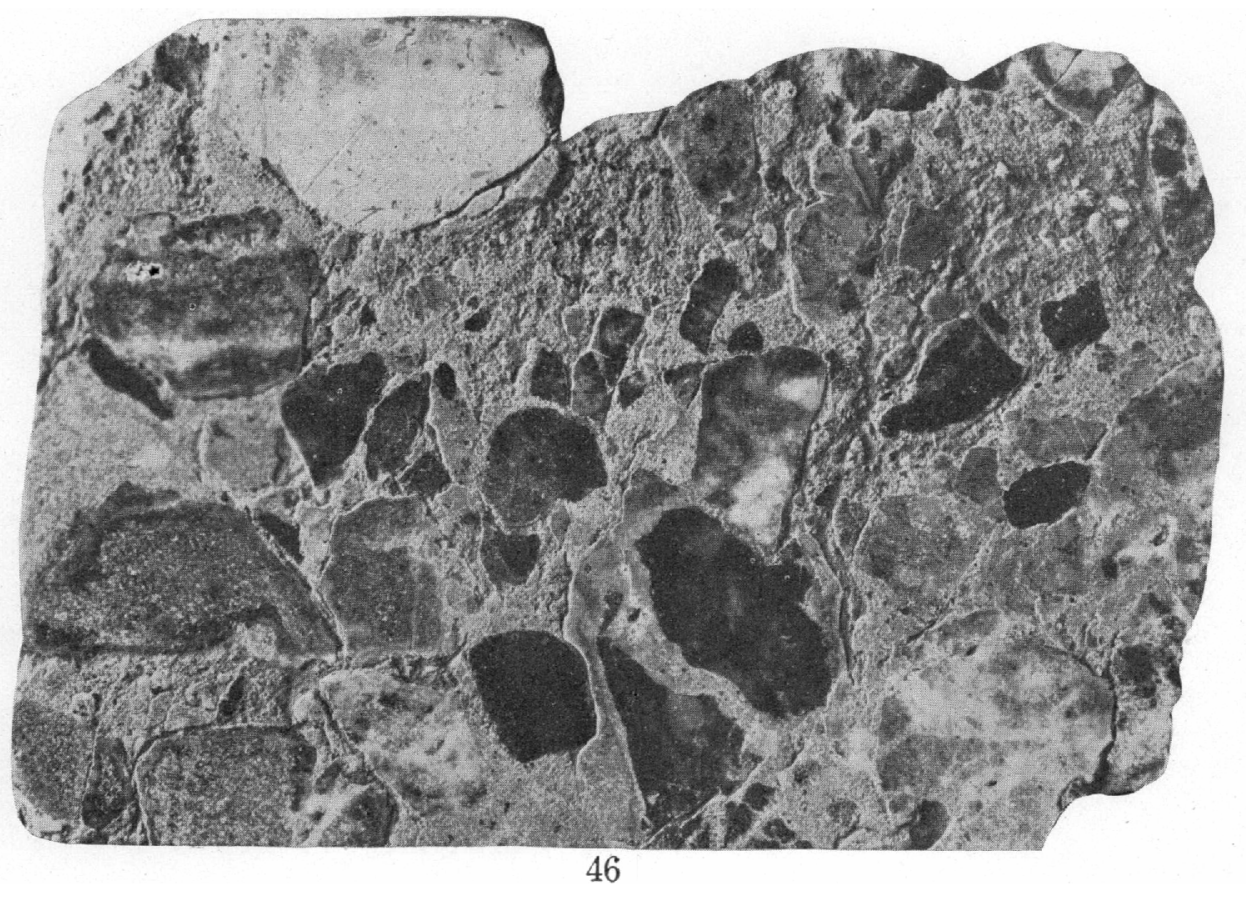


